\title{
Influence of dietary fat source and feeding duration on finishing pig growth performance, carcass composition, and fat quality ${ }^{1,2}$
}

\author{
E. W. Stephenson, * M. A. Vaughn,* D. D. Burnett,* C. B. Paulk,* M. D. Tokach,* \\ S. S. Dritz, $\dagger$ J. M. DeRouchey,* R. D. Goodband, *3 J. C. Woodworth,* and J. M. Gonzalez* \\ *Department of Animal Sciences and Industry, College of Agriculture and $†$ Department of Diagnostic Medicine/ \\ Pathobiology, College of Veterinary Medicine, Kansas State University, Manhattan 66506-0201
}

\begin{abstract}
A total of 160 finishing pigs (PIC $327 \times$ 1050; initially $45.6 \mathrm{~kg}$ ) were used in an 84-d experiment to evaluate the effects of dietary fat source and feeding duration on growth performance, carcass characteristics, and carcass fat quality. There were 2 pigs per pen with 8 pens per treatment. The 10 dietary treatments were a corn-soybean meal control diet with no added fat and a $3 \times 3$ factorial with main effects of fat source (4\% tallow, $4 \%$ soybean oil, or a blend of $2 \%$ tallow and $2 \%$ soybean oil) and feeding duration (d 0 to 42,42 to 84 , or 0 to 84 ). The control cornsoybean meal diet was fed in place of added fat diets when needed for duration treatment purposes. On d 0 , 1 pig was identified in each pen and fat biopsy samples of the back, belly, and jowl were collected on d 0,41 , and 81 for fatty acid analysis. At the conclusion of the study, all pigs were harvested, carcass characteristics were determined, and back, belly, and jowl fat samples were collected for analysis. Overall (d 0 to 84), there were no differences among pigs fed the different fat sources for growth and carcass characteristics; however, pigs fed diets with added fat for the entire study had improved $(P=0.036) \mathrm{G}: \mathrm{F}$ compared with pigs fed the
\end{abstract}

control diet without added fat. Pigs fed supplemental fat throughout the entire study also had improved $(P<$ $0.05) \mathrm{ADG}$ and G:F as well as heavier d-84 BW $(P=$ 0.006) compared with pigs fed additional fat during only 1 period. Adding fat for the entire study increased $(P=0.032)$ backfat and tended to reduce $(P=0.079)$ the fat free lean index compared with pigs fed the control diet without added fat. Added fat also increased $(P<0.05)$ the iodine value (IV) when compared with pigs fed the control diet. Increasing the feeding duration of soybean oil lowered MUFA and increased PUFA concentrations for all fat depots, whereas these values remained relatively unchanged by the addition of tallow (duration $\times$ fat source interactions, $P<0.05$ ). Our study failed to show any feeding period $\times$ fat source interactions $(P<0.05)$ in fatty acid composition or IV for jowl fat, whereas this interaction occurred for belly fat and backfat, which would indicate a longer turnover rate for jowl fat. In conclusion, feeding additional fat improved ADG and G:F; however, feeding soybean oil for an increased duration, either alone or in combination with tallow, negatively affected the fatty acid composition and IV of different fat depots.

Key words: carcass, finishing pig, growth, iodine value, soybean oil, tallow

\section{INTRODUCTION}

\footnotetext{
${ }^{1}$ Contribution number 16-017-J from the Kansas Agric. Exp. Sta., Manhattan, KS 66506-0210.

${ }^{2}$ Appreciation is expressed to the National Pork Board for partial financial support.

${ }^{3}$ Corresponding author: goodband@ksu.edu

Received July 9, 2015.

Accepted April 23, 2016.
}

The addition of fats and oils in swine diets has been shown to decrease feed intake, increase ADG, and improve feed efficiency in grow-finish pigs (De la Llata et al., 2001). However, carcass quality in pork can be negatively affected by dietary ingredients and fat sources, as the fatty acid profile of the pork fat is related to those in the diet (Wood et al., 2004). Iodine value (IV) is commonly used by pork processors to evaluate pork fat quality as an indication of the proportion 
of unsaturated fatty acids present. Processors that are measuring IV target a value of 73 to $75 \mathrm{~g} / 100 \mathrm{~g}$, with high values being less ideal (Benz et al., 2010). High IV values create challenges for processors, as the "soft fat" can create problems in belly slicing and reduce shelf life due to oxidative rancidity (NRC, 2012).

Fat source (Apple et al., 2009b), withdrawal periods (Xu et al., 2010), and duration of feeding unsaturated feeds (Browne et al., 2013a) has been shown to affect IV. It has been suggested that removing unsaturated fat sources in late finishing diets could alleviate some of the negative effects of these fat sources on carcass and fat quality (Benz et al., 2011a). Limiting the duration of feeding unsaturated fats and substituting a saturated fat, such as beef tallow, in late finishing has shown promise for positively affecting IV (Browne et al., 2013a; Kellner et al., 2014).

Paulk et al. (2015) performed a meta-analysis to generate predictive IV equations for various fat depots in swine. This study was used to validate those equations. A portion of the data from this study was reported by Paulk et al. (2015) with the remainder being reported herein. This study was conducted to determine the effects of feeding soybean oil, beef tallow, or a blend of the 2 , as well as feeding duration, on finishing pig growth performance, carcass characteristics, and IV of belly and jowl fat and backfat. The change in fatty acid profile throughout the duration of the study was also evaluated.

\section{MATERIALS AND METHODS}

\section{General}

The Kansas State University Institutional Animal Care and Use Committee approved the protocol used in this experiment. A total of 160 finishing pigs (PIC $327 \times$ 1050 ) with an average initial BW of $45.6 \pm 0.25 \mathrm{~kg}$ were housed at the Kansas State University Swine Teaching and Research Center finishing barn (Manhattan, KS). The finishing barn was an environmentally controlled facility with $2.32-\mathrm{m}^{2}$ slatted-floor pens. Each pen was equipped with a dry self-feeder and a nipple waterer to provide ad libitum access to feed and water. Upon placement in the barn, pigs were fed a common cornsoybean meal-based diet without added fat prior to the start of the experiment.

\section{Animals and Diets}

Pens of pigs were blocked by sex and BW and allotted to 1 of 10 dietary treatments, with 2 barrows or 2 gilts housed in each pen with a total of 8 pens per treatment. Dietary treatments consisted of a corn-soybean meal control diet with no added fat or a $3 \times 3$ facto- rial arrangement of treatments with main effects of fat source ( $4 \%$ tallow, $4 \%$ soybean oil, or a blend of $2 \%$ tallow and $2 \%$ soybean oil) and feeding duration ( $\mathrm{d} 0$ to 42,42 to 84 , or 0 to 84 ). The control corn-soybean meal diet was fed in place of added fat diets when needed for duration treatment purposes. Diets were formulated to be fed in 3 phases (d 0 to 28,28 to 56 , and 56 to 84 ; Table 1). Soybean oil, tallow, and a blend of the 2 were added to provide diets high in unsaturated fatty acids, high in SFA, or a blend of the 2, respectively. A constant standardized ileal digestible Lys:NE ratio was maintained within each phase by increasing soybean meal in the diets with added fat. Diets were formulated by using NRC (2012) composition values for ingredients. Dietary treatments were prepared at the Kansas State University O. H. Kruse Feed Technology Innovation Center (Manhattan, KS).

\section{Sample Collection}

Samples of each diet were collected from feeders for each phase and treatment. Samples were then subsampled and analyzed for DM (method 934.01; AOAC, 2006), CP (method 990.03; AOAC, 2006), crude fibe (method 978.10; AOAC, 2006), crude fat (method 920.39; AOAC, 2006), ash (method 942.05; AOAC, 2006), and ADF and NDF (Van Soest, 1963; Ward Laboratories Inc., Kearney, NE; Table 2).

Pigs and feeders were weighed approximately every 2 wk to calculate ADG, ADFI, and G:F. Prior to marketing, pigs were individually tattooed so that carcass measurements could be collected on an individual pig basis. On d 84, final pig weights were taken and pigs were transported approximately $530 \mathrm{~km}$ to a commercial packing facility for harvest (Sioux-Preme Packing Co., Sioux Center, IA). Fat samples (jowl, 10th rib, and belly) were collected at the commercial packing facility as close to the d-81 biopsy site as possible (see procedure below). Carcass measurements taken at the plant included HCW, 10th rib loin eye area, and backfat depth.

One pig from every pen was identified and fat biopsy samples were collected and analyzed for fatty acid and IV on d 0,41 , and 81 . For sample collection, pigs were restrained using a snare, the hair was clipped in each location (jowl, belly, and loin), and $1 \mathrm{~mL}$ of lidocaine was administered to the sample location. The location of the first backfat biopsy location was approximately at the first lumbar vertebra. The location was determined by following the curvature of the last rib of the animal to where it met the vertebral column, moving $1.27 \mathrm{~cm}$ toward the posterior of the animal and $1.27 \mathrm{~cm}$ lateral from midline. For subsequent collections, the location moved in a straight line $2.54 \mathrm{~cm}$ toward the posterior of the animal from the previous biopsy site. The land- 
Table 1. Phase 1, 2, and 3 diet composition (as-fed basis) ${ }^{1}$

\begin{tabular}{|c|c|c|c|c|c|c|}
\hline \multirow[b]{2}{*}{ Item } & \multicolumn{2}{|c|}{ Phase 1} & \multicolumn{2}{|c|}{ Phase 2} & \multicolumn{2}{|c|}{ Phase 3} \\
\hline & Control & Added fat & Control & Added fat & Control & Added fat \\
\hline \multicolumn{7}{|l|}{ Ingredient, \% } \\
\hline Corn & 76.37 & 69.40 & 80.70 & 74.06 & 84.00 & 77.75 \\
\hline Soybean meal, $46.5 \% \mathrm{CP}$ & 20.95 & 23.90 & 17.00 & 19.60 & 14.00 & 16.25 \\
\hline Fat source ${ }^{2}$ & - & 4.00 & - & 4.00 & - & 4.00 \\
\hline Monocalcium, 21\% P & 0.49 & 0.48 & 0.38 & 0.38 & 0.31 & 0.31 \\
\hline Limestone & 1.05 & 1.05 & 1.00 & 1.00 & 0.90 & 0.90 \\
\hline Salt & 0.35 & 0.35 & 0.35 & 0.35 & 0.35 & 0.35 \\
\hline Vitamin premix ${ }^{3}$ & 0.15 & 0.15 & 0.10 & 0.10 & 0.08 & 0.08 \\
\hline Trace mineral premix ${ }^{4}$ & 0.15 & 0.15 & 0.10 & 0.10 & 0.08 & 0.08 \\
\hline L-Lys $\mathrm{HCl}$ & 0.28 & 0.28 & 0.23 & 0.23 & 0.20 & 0.20 \\
\hline DL-Met & 0.05 & 0.07 & 0.01 & 0.03 & - & - \\
\hline L-Thr & 0.08 & 0.09 & 0.05 & 0.07 & - & - \\
\hline Phytase ${ }^{5}$ & 0.08 & 0.08 & 0.08 & 0.08 & 0.08 & 0.08 \\
\hline Total & 100.00 & 100.00 & 100.00 & 100.00 & 100.00 & 100.00 \\
\hline \multicolumn{7}{|l|}{ Calculated analysis } \\
\hline \multicolumn{7}{|c|}{ Standard ileal digestible (SID) AA, \% } \\
\hline Lys & 0.91 & 0.98 & 0.78 & 0.83 & 0.68 & 0.73 \\
\hline Ile:Lys, \% & 63 & 63 & 66 & 65 & 67 & 67 \\
\hline Leu:Lys, \% & 143 & 138 & 157 & 150 & 168 & 160 \\
\hline Met:Lys, \% & 32 & 32 & 29 & 30 & 31 & 31 \\
\hline Met + Cys:Lys, $\%$ & 58 & 58 & 58 & 58 & 61 & 60 \\
\hline Thr:Lys, \% & 63 & 63 & 64 & 64 & 65 & 65 \\
\hline Trp:Lys, \% & 18 & 18 & 18 & 18 & 18 & 18 \\
\hline Val:Lys, $\%$ & 71 & 70 & 75 & 74 & 78 & 76 \\
\hline SID Lys:NE, g/Mcal & 3.65 & 3.65 & 3.08 & 3.08 & 2.68 & 2.68 \\
\hline $\mathrm{ME}, \mathrm{kcal} / \mathrm{kg}$ & 3,301 & 3,506 & 3,312 & 3,517 & 3,322 & 3,528 \\
\hline $\mathrm{NE}, \mathrm{kcal} / \mathrm{kg}$ & 2,492 & 2,670 & 2,521 & 2,701 & 2,544 & 2,726 \\
\hline Total Lys, $\%$ & 1.03 & 1.10 & 0.88 & 0.94 & 0.78 & 0.83 \\
\hline $\mathrm{CP}, \%$ & 16.6 & 17.5 & 15.0 & 15.7 & 13.8 & 14.4 \\
\hline $\mathrm{Ca}, \%$ & 0.54 & 0.55 & 0.50 & 0.50 & 0.44 & 0.45 \\
\hline $\mathrm{P}, \%$ & 0.45 & 0.45 & 0.41 & 0.41 & 0.38 & 0.38 \\
\hline Available P, \% & 0.26 & 0.26 & 0.24 & 0.24 & 0.22 & 0.22 \\
\hline Crude fiber, $\%$ & 2.3 & 2.3 & 2.3 & 2.2 & 2.2 & 2.2 \\
\hline
\end{tabular}

${ }^{1}$ Phase 1,2 , and 3 diets were fed from d 0 to 28 , d 28 to 56 , and d 56 to 84 , respectively.

${ }^{2}$ Fat sources were tallow, soybean oil, or a blend of $2 \%$ tallow and $2 \%$ soybean oil.

${ }^{3}$ Provided, per kilogram of premix, 4,409,200 IU vitamin A, 551,150 IU vitamin $\mathrm{D}_{3}$, 17,637 IU vitamin E, 1,764 mg vitamin K, 3,307 mg riboflavin, $11,023 \mathrm{mg}$ pantothenic acid, $19,841 \mathrm{mg}$ niacin, and $15.4 \mathrm{mg}$ vitamin $\mathrm{B}_{12}$.

${ }^{4}$ Provided, per kilogram of premix, $26.5 \mathrm{~g} \mathrm{Mn}$ from manganese oxide, $110 \mathrm{~g}$ Fe from iron sulfate, $110 \mathrm{~g} \mathrm{Zn}$ from zinc sulfate, $11 \mathrm{~g}$ Cu from copper sulfate, $198 \mathrm{mg}$ I from calcium iodate, and $198 \mathrm{mg}$ Se from sodium selenite.

${ }^{5}$ Phytase was added to all diets at a rate of $0.08 \%$ to provide 778.4 phytase units $/ \mathrm{kg}$ of complete diet and a $0.12 \%$ P release.

mark for the first jowl biopsy site was approximately at the angle of the mandible. The location was moved in a straight line $2.54 \mathrm{~cm}$ toward the posterior of the animal from the previous biopsy site for subsequent biopsies. The location of the first belly biopsy was directly ventral relative to the backfat biopsy. The location was determined by following the curvature of the last rib toward where it terminates on the underbelly, moving $1.27 \mathrm{~cm}$ toward the posterior of the animal and $1.27 \mathrm{~cm}$ lateral from midline. For subsequent collections on d 41 and 81 , locations were moved in a straight line $2.54 \mathrm{~cm}$ toward the posterior of the animal from the previous biopsy site.
After adequate time was given for the biopsy site to be desensitized, an 8-gauge needle was used to pierce the skin, and a 10-gauge biopsy needle was used to collect approximately $250 \mathrm{mg}$ of tissue per biopsy site. Fat tissue samples were snap frozen in liquid $\mathrm{N}$ and then stored in a $-80^{\circ} \mathrm{C}$ freezer until analysis.

\section{Fat Quality Analysis}

Both feed and fat depot samples were analyzed according to Palmquist and Jenkins (2003) with revisions. Samples were analyzed by mixing $0.025 \mathrm{~g}$ of dry sample 
Table 2. Diet analysis (as-fed basis) $)^{1}$

\begin{tabular}{|c|c|c|c|c|c|c|c|c|c|c|c|c|}
\hline \multirow[b]{3}{*}{ Item, ${ }^{3} \%$} & \multicolumn{12}{|c|}{ Diets $^{2}$} \\
\hline & \multicolumn{4}{|c|}{ Phase 1} & \multicolumn{4}{|c|}{ Phase 2} & \multicolumn{4}{|c|}{ Phase 3} \\
\hline & Control & Tallow & Blend & Soy & Control & Tallow & Blend & Soy & Control & Tallow & Blend & Soy \\
\hline$\overline{\mathrm{DM}}$ & 89.9 & 90.7 & 90.0 & 90.0 & 89.7 & 90.0 & 90.0 & 89.7 & 89.5 & 90.2 & 89.5 & 89.8 \\
\hline $\mathrm{CP}$ & 17.9 & 18.7 & 17.5 & 18.3 & 16.1 & 16.0 & 16.3 & 16.7 & 15.0 & 15.2 & 15.3 & 14.9 \\
\hline $\mathrm{ADF}$ & 2.6 & 3.6 & 3.3 & 3.4 & 3.3 & 3.2 & 3.0 & 3.4 & 1.9 & 2.4 & 2.8 & 2.3 \\
\hline $\mathrm{NDF}$ & 6.5 & 8.0 & 8.0 & 6.6 & 5.9 & 5.2 & 6.0 & 5.4 & 7.1 & 8.4 & 8.4 & 6.8 \\
\hline Crude fiber & 1.9 & 2.7 & 2.9 & 2.4 & 1.5 & 2.4 & 2.4 & 2.1 & 2.0 & 2.5 & 2.9 & 2.5 \\
\hline $\mathrm{NFE}^{4}$ & 63.1 & 58.2 & 59.4 & 58.2 & 65.0 & 61.5 & 60.9 & 61.4 & 66.3 & 62.1 & 62.3 & 63.0 \\
\hline Ether extract & 3.0 & 6.7 & 6.2 & 6.5 & 2.3 & 6.3 & 6.7 & 5.5 & 3.1 & 7.1 & 5.9 & 6.4 \\
\hline Ash & 3.85 & 4.20 & 4.27 & 4.29 & 3.65 & 3.64 & 3.71 & 3.37 & 3.64 & 3.87 & 3.78 & 3.59 \\
\hline
\end{tabular}

${ }^{1}$ Phase 1,2 , and 3 diets were fed from d 0 to 28 , d 28 to 56 , and d 56 to 84 , respectively.

${ }^{2} \mathrm{Control}=$ no added fat; Tallow $=4 \%$ beef tallow; Blend $=2 \%$ tallow and $2 \%$ soybean oil; Soy $=4 \%$ soybean oil.

${ }^{3}$ Values represent the mean of 1 composite sample of each diet.

${ }^{4} \mathrm{NFE}=$ nitrogen-free extract.

with $2 \mathrm{~mL}$ of benzene containing methyl tridecanoate as internal standard (2 mg/mL of benzene, Fluka 91558; Sigma-Aldrich, St. Louis, MO) and $3 \mathrm{~mL}$ methanolic $\mathrm{HCl}$ before being flushed with nitrogen. Tubes were then capped, vortexed, heated for $2 \mathrm{~h}$ at $70^{\circ} \mathrm{C}$, and vortexed every $30 \mathrm{~min}$ during heating. Tubes were cooled to room temperature, mixed with $5 \mathrm{~mL} 6 \% \mathrm{~K}_{2} \mathrm{CO}_{3}$ and $2 \mathrm{~mL}$ benzene, vortexed, and then centrifuged at $500 \times g$ for $5 \mathrm{~min}$ at $23^{\circ} \mathrm{C}$. The organic solvent layer was then analyzed by gas chromatography. An Agilent gas chromatograph (model 7890A; Agilent Technologies, Inc., Santa Clara, CA) equipped with a HP-88 J\&W Agilent GC capillary column ( $30 \mathrm{~m}$ by $0.25 \mathrm{~mm}$ by $0.20 \mu \mathrm{m}$ film; Agilent Technologies, Inc.) was used for the analysis. The injection temperature was $250^{\circ} \mathrm{C}$, the split ratio was $1: 100$, and the flame-ionization detector was set at $280^{\circ} \mathrm{C}$ and used hydrogen $(35 \mathrm{~mL} / \mathrm{min})$, air ( $400 \mathrm{~mL} / \mathrm{min})$, makeup helium $(25 \mathrm{~mL} / \mathrm{min})$, and helium carrier gas at constant flow $(0.91 \mathrm{~mL} / \mathrm{min})$. The oven temperature program was set as follows: initial temperature of $80^{\circ} \mathrm{C}$, hold $1 \mathrm{~min}$, increase $14^{\circ} \mathrm{C} / \mathrm{min}$ to $240^{\circ} \mathrm{C}$, and hold $3 \mathrm{~min}$. Supelco 37 Component FAME Mix (47885-U Supelco; SigmaAldrich) was used as a standard. Calculation of IV from the fatty acid profile was done according to the following equation: $\mathrm{IV}=(\% \mathrm{C} 16: 1) \times 0.9502+(\% \mathrm{C} 18: 1) \times$ $0.8598+(\% \mathrm{C} 18: 2) \times 1.7315+(\% \mathrm{C} 18: 3) \times 2.6152+$ $(\% \mathrm{C} 20: 1) \times 0.7852+(\% \mathrm{C} 20: 4) \times 3.2008+(\% \mathrm{C} 20: 5)$ $\times 4.0265+(\% \mathrm{C} 22: 1) \times 0.7225+(\% \mathrm{C} 22: 5) \times 3.6974+$ $(\mathrm{C} 22: 6) \times 4.4632(\mathrm{NRC}, 2012)$.

\section{Statistical Analysis}

All growth performance and carcass data was analyzed as a randomized complete block design using the MIXED procedure of SAS (SAS Inst. Inc., Cary, NC) with pen as the experimental unit. Pens were blocked by BW within sex. Block was included as a random effect.
Sex, fat source, feeding duration, and all their possible interactions served as fixed effects. Feeding duration refers to the length of time fat was added into the diet (42 or 84 d), whereas feeding period refers to when fat was added into the diet (period 1 was $\mathrm{d} 0$ to 42 and period 2 was $\mathrm{d} 42$ to 84). Hot carcass weight was used as a covariate to analyze backfat, loin depth, and percentage lean. Contrast statements for both periods 1 and 2 consisted of 1) no added fat vs. added fat, 2) tallow vs. blend, 3) blend vs. soy oil, and 4) tallow vs. soy oil. Contrast statements for the overall growth performance and carcass characteristics were 1) no added fat vs. added fat both periods, 2) added fat both periods vs. added fat only during a single period, 3) added fat only during period $1 \mathrm{vs.} \mathrm{added} \mathrm{fat}$ only during period 2,4) tallow vs. blend, 5) blend vs. soy oil, and 6) tallow vs. soy oil. The statistical structure was the same for fatty acid composition except that day of sample collection and all possible interactions were included as fixed effects. Day was included as the repeated variable with pig as the subject. The covariance structure modified first-order autoregressive model was used. For fatty acid composition, contrast statements evaluating the interactions of feeding duration, feeding period, and fat source were used while also comparing the main effect of fat source. Statistical significance was determined at $P<$ 0.05 and $P$-values falling within $P>0.05$ and $P<0.10$ were defined as a trend or tendency.

\section{RESULTS}

\section{Diet Analysis}

Diet analyses revealed that nutrients were similar to calculated values considering normal analytical variation. Chemical analyses of tallow and soybean oil used in this study were similar to expectations and indicated large differences in total SFA, specifically 45.7 
Table 3. Fatty acid analysis of ingredients and diets

\begin{tabular}{|c|c|c|c|c|c|c|c|c|c|c|c|c|c|c|}
\hline \multirow[b]{3}{*}{ Item } & & & \multicolumn{12}{|c|}{$\overline{\text { Diets }^{1}}$} \\
\hline & \multicolumn{2}{|c|}{ Ingredients } & \multicolumn{3}{|c|}{ Phase 1} & \multicolumn{4}{|c|}{ Phase 2} & \multicolumn{4}{|c|}{ Phase 3} & \multirow[b]{2}{*}{ Soy } \\
\hline & Tallow & Soy oil & Control & Tallow & Blend & Soy & Control & Tallow & Blend & Soy & Control & Tallow & Blend & \\
\hline$\overline{\mathrm{C} 14: 0, \%}$ & 2.94 & 0.08 & 0.06 & 1.51 & 0.81 & 0.09 & 0.09 & 1.56 & 0.94 & 0.09 & 0.05 & 1.52 & 1.09 & 0.08 \\
\hline $\mathrm{C} 16: 0, \%$ & 24.09 & 9.61 & 16.83 & 20.78 & 16.92 & 12.85 & 16.78 & 21.06 & 17.42 & 13.59 & 16.17 & 20.80 & 18.38 & 13.36 \\
\hline $\mathrm{C} 16: 0, \%$ & 3.77 & 0.11 & 0.15 & 1.91 & 1.14 & 0.14 & 0.20 & 1.99 & 1.28 & 0.13 & 0.14 & 1.98 & 1.38 & 0.12 \\
\hline $\mathrm{C} 18: 0, \%$ & 16.91 & 4.34 & 2.48 & 10.49 & 7.00 & 3.68 & 2.56 & 10.50 & 7.87 & 3.89 & 2.01 & 10.40 & 8.85 & 3.86 \\
\hline C18:1 cis- $9, \%$ & 38.38 & 24.52 & 20.99 & 28.51 & 25.88 & 23.06 & 21.61 & 29.70 & 25.63 & 21.47 & 22.45 & 28.71 & 26.15 & 21.79 \\
\hline $\mathrm{C} 18: 2 \mathrm{n}-6, \%$ & 5.07 & 51.80 & 51.11 & 27.36 & 39.08 & 50.77 & 50.31 & 26.32 & 36.98 & 50.42 & 52.14 & 27.12 & 35.17 & 50.60 \\
\hline C18:3n-3, \% & 0.32 & 6.81 & 2.31 & 1.45 & 3.01 & 4.71 & 2.47 & 1.41 & 3.80 & 6.07 & 2.07 & 1.61 & 2.94 & 5.99 \\
\hline $\mathrm{C} 20: 0, \%$ & 0.16 & 0.33 & 0.43 & 0.27 & 0.33 & 0.38 & 0.39 & 0.25 & 0.29 & 0.36 & 0.37 & 0.26 & 0.29 & 0.37 \\
\hline $\mathrm{C} 20: 1, \%$ & 0.26 & $\mathrm{ND}^{9}$ & ND & ND & ND & ND & ND & ND & ND & ND & $\mathrm{ND}$ & ND & ND & ND \\
\hline Other fatty acids, $\%$ & 8.10 & 2.40 & 5.63 & 7.70 & 5.83 & 4.33 & 5.60 & 7.21 & 5.79 & 3.98 & 4.61 & 7.59 & 5.75 & 3.82 \\
\hline Total SFA, ${ }^{2} \%$ & 45.72 & 15.10 & 24.24 & 36.48 & 28.13 & 19.79 & 24.19 & 36.20 & 29.27 & 20.50 & 22.24 & 36.03 & 31.20 & 20.14 \\
\hline Total MUFA, ${ }^{3} \%$ & 47.57 & 26.04 & 22.15 & 34.10 & 29.34 & 24.48 & 22.86 & 35.45 & 29.53 & 22.82 & 23.43 & 34.61 & 30.26 & 23.09 \\
\hline Total PUFA, ${ }^{4} \%$ & 6.71 & 58.86 & 53.61 & 29.43 & 42.52 & 55.73 & 52.96 & 28.35 & 41.20 & 56.68 & 54.33 & 29.36 & 38.54 & 56.77 \\
\hline UFA:SFA ratio ${ }^{5}$ & 1.19 & 5.62 & 3.13 & 1.74 & 2.55 & 4.05 & 3.13 & 1.76 & 2.42 & 3.88 & 3.50 & 1.78 & 2.21 & 3.97 \\
\hline PUFA:SFA ratio ${ }^{6}$ & 0.15 & 3.90 & 2.21 & 0.81 & 1.51 & 2.82 & 2.19 & 0.78 & 1.41 & 2.76 & 2.44 & 0.81 & 1.24 & 2.82 \\
\hline Iodine value,${ }^{7} \mathrm{~g} / 100 \mathrm{~g}$ & 49.9 & 129.9 & 113.4 & 80.2 & 100.7 & 121.2 & 113.0 & 79.5 & 99.3 & 122.7 & 115.7 & 80.5 & 94.4 & 123.1 \\
\hline Analyzed IVP8 & 499.4 & $1,298.9$ & 34.0 & 53.8 & 62.4 & 78.8 & 26.0 & 50.1 & 66.5 & 67.5 & 35.9 & 57.2 & 55.7 & 78.8 \\
\hline
\end{tabular}

${ }^{1}$ Control $=$ no added fat; Tallow $=4 \%$ beef tallow; Blend $=2 \%$ tallow and $2 \%$ soybean oil; Soy $=4 \%$ soybean oil.

${ }^{2}$ Total SFA $=([\mathrm{C} 6: 0]+[\mathrm{C} 8: 0]+[\mathrm{C} 10: 0]+[\mathrm{C} 11: 0]+[\mathrm{C} 12: 0]+[\mathrm{C} 14: 0]+[\mathrm{C} 15: 0]+[\mathrm{C} 16: 0]+[\mathrm{C} 17: 0]+[\mathrm{C} 18: 0]+[\mathrm{C} 20: 0]+[\mathrm{C} 21: 0]+[\mathrm{C} 22: 0]+$ $[\mathrm{C} 23: 0]+[\mathrm{C} 24: 0])$; brackets indicate concentration.

${ }^{3}$ Total MUFA $=([\mathrm{C} 14: 1]+[\mathrm{C} 15: 1]+[\mathrm{C} 16: 1]+[\mathrm{C} 18: 1 n-99]+[\mathrm{C} 18: 1 n-9 t]+[\mathrm{C} 18: 1 n-11 t]+[\mathrm{C} 18: 1 n-11 c]+[\mathrm{C} 20: 1]+[\mathrm{C} 22: 1 n-9]+[\mathrm{C} 24: 1]) ;$ brackets indicate concentration.

${ }^{4}$ Total PUFA $=([\mathrm{C} 18: 2 n-6]+[\mathrm{C} 18: 3 n-3]+[\mathrm{C} 18: 3 n-6]+[$ CLA 9c, 11t] $+[$ CLA 10t,12c] $+[$ CLA 9c, 11c] $+[$ CLA 9t, 11t] $+[$ C20:3n-6] $+[$ C $20: 3 n-3]+$ $[\mathrm{C} 22: 2]+[\mathrm{C} 20: 5 n-3]+[\mathrm{C} 22: 5 n-3]+[\mathrm{C} 22: 6 n-3]$; brackets indicate concentration.

${ }^{5} \mathrm{UFA}=$ unsaturated fatty acids; UFA:SFA $=($ total MUFA + PUFA $) /$ total SFA.

${ }^{6} \mathrm{PUFA}: \mathrm{SFA}=$ total PUFA/total SFA

${ }^{7}$ Calculated as iodine value $=[\mathrm{C} 16: 1] \times 0.950+[\mathrm{C} 18: 1] \times 0.860+[\mathrm{C} 18: 2] \times 1.732+[\mathrm{C} 18: 3] \times 2.616+[\mathrm{C} 20: 1] \times 0.785+[\mathrm{C} 20: 4] \times 3.201+[\mathrm{C} 22: 1] \times$ $0.723+[\mathrm{C} 22: 5] \times 3.697+[\mathrm{C} 22: 6] \times 4.463 ;$ brackets indicate concentration.

${ }^{8} \mathrm{IVP}=$ iodine value product; iodine values of dietary lipids and diets were calculated from analyzed fatty acid composition $\times \%$ analyzed lipids $\times 0.10$.

${ }^{9} \mathrm{ND}=$ none detected.

and $15.1 \%$ for tallow and soybean oil, respectively (Table 3). Conversely, total PUFA concentrations were 6.7 and $58.9 \%$ for tallow and soybean oil, respectively. As a result, IV for soybean oil, $129.9 \mathrm{~g} / 100 \mathrm{~g}$, was more than double that of tallow, $49.9 \mathrm{~g} / 100 \mathrm{~g}$. Diet analyses for each of the 3 phases were consistent among one another, as diets with $4 \%$ tallow maintained greater total SFA concentrations relative to $4 \%$ soybean oil diets, with diets having a blend of the 2 sources being intermediate. In contrast, 4\% soybean oil diets had greater concentrations of total PUFA in comparison with $4 \%$ tallow diets, with the blend of the 2 being intermediate.

\section{Growth and Carcass Characteristics}

From d 0 to 42, pigs fed diets with added fat had increased $(P=0.005)$ ADG and improved $(P=0.001)$ $\mathrm{G}: F$ compared with pigs fed diets not containing added fat (Table 4). Pigs fed diets with added tallow or soybean oil had improved $(P<0.05) \mathrm{G}: \mathrm{F}$ compared with pigs fed a diet containing a blend of soybean oil and tallow. During period 2 (d 42 to 84), pigs tended $(P=0.052)$ to have increased ADG and had improved $(P=0.001) \mathrm{G}: \mathrm{F}$ when fed added fat. No differences were found among fat sources during period 2 .

Overall (d 0 to 84), pigs fed added fat in both periods had increased $(P=0.018)$ ADG and improved $(P=$ $0.042) \mathrm{G}: \mathrm{F}$ as well as greater final BW $(P=0.006)$ compared with pigs fed additional fat during only a single period (d 0 to 42 or 42 to 84 ). In addition, pigs fed fat in both periods had improved $(P=0.036) \mathrm{G}: \mathrm{F}$ compared with pigs fed diets not containing added fat. Pigs fed diets with soybean oil tended to have improved $(P=0.092) \mathrm{G}: \mathrm{F}$ vs. those fed a diet containing a blend of soybean oil and tallow.

For carcass characteristics, adding fat from $\mathrm{d} 0$ to 84 increased $(P=0.032)$ backfat and tended to reduce $(P=0.079)$ fat free lean index compared with pigs fed diets with no added fat. There were no differences $(P>0.10)$ in HCW, percentage yield, or loin eye area among treatments. 
Table 4. Effects of source and duration of added fat on growth performance and carcass characteristics of finishing pigs ${ }^{1}$

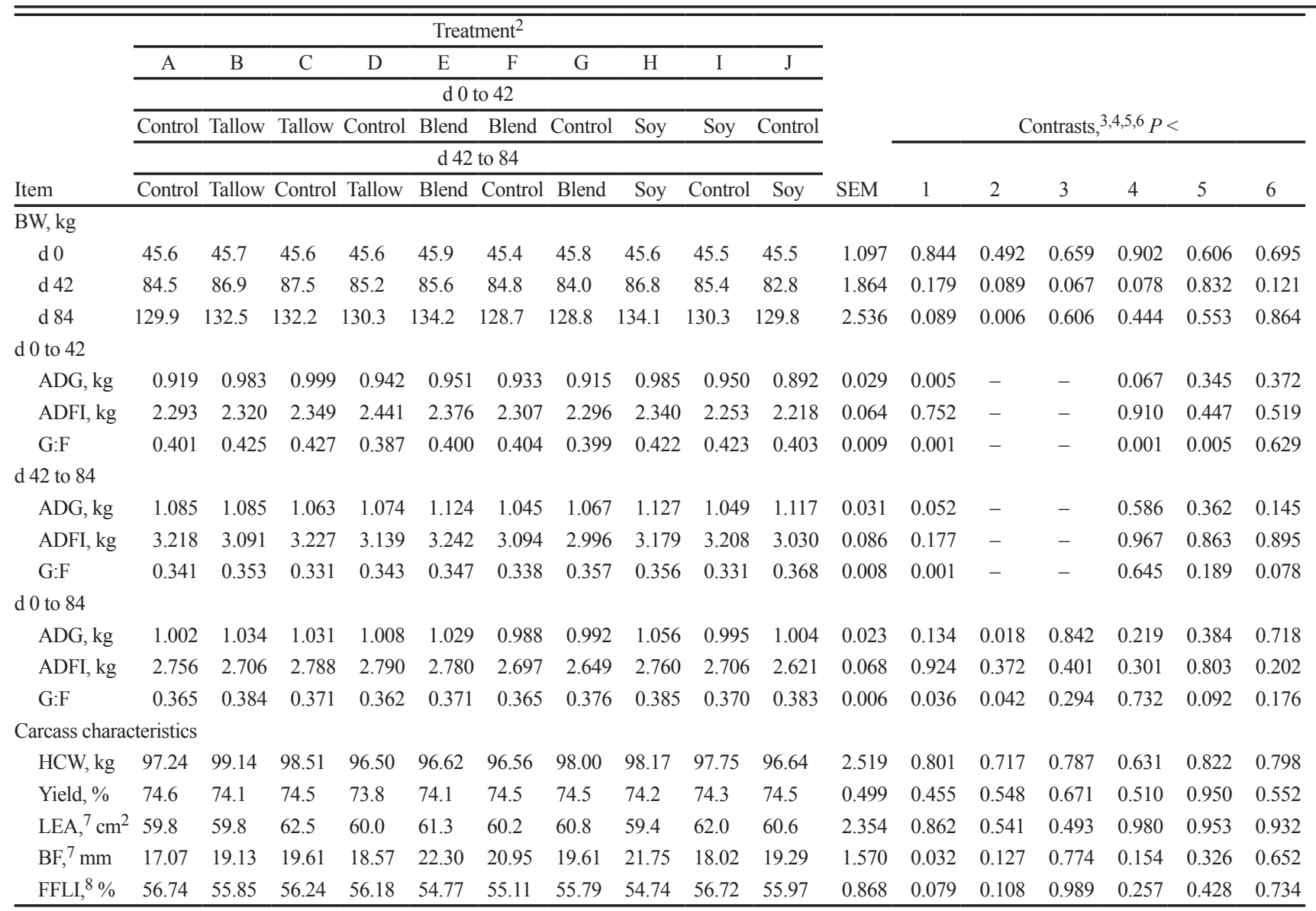

${ }^{1}$ A total of 160 finishing pigs (PIC $337 \times 1050$; initial BW of $45.6 \mathrm{~kg}$ ) were used in an 84-d finishing trial with 2 pigs per pen and 8 pens per treatment.

${ }^{2}$ Control $=$ no added fat; Tallow $=4 \%$ beef tallow; Blend $=2 \%$ tallow and $2 \%$ soybean oil; Soy $=4 \%$ soybean oil.

${ }^{3}$ There were no fat or fat source interactions $P>0.05$.

${ }^{4}$ The period 1 ( $\mathrm{d} 0$ to 42 ) contrast statements are as follows $1=$ no added fat vs. added fat (treatments A, D, G, and J vs. B, C, E, F, H, and I); 4 = tallow vs. blend (treatments B and C vs. E and F); 5 = blend vs. soy oil (treatments E and F vs. H and I); and $6=$ tallow vs. soy oil (treatments B and C vs. H and I).

${ }^{5}$ The period 2 ( $\mathrm{d} 42$ to 84 ) contrast statements are as follows $1=$ no added fat vs. added fat (treatments A, C, F, and I vs. B, D, E, G, H, and J); 4 = tallow vs. blend (treatments B and D vs. E and G); 5 = blend vs. soy oil (treatments $\mathrm{E}$ and $\mathrm{G}$ vs. $\mathrm{H}$ and J); and $6=$ tallow vs. soy oil (treatments B and D vs. H and J).

${ }^{6}$ The overall ( $\mathrm{d} 0$ to 84 ) and carcass characteristics contrast statements are as follows: 1 = no added fat vs. added fat both periods (treatment A vs. B, E, and $\mathrm{H}$ ); 2 = added fat both periods vs. added fat only during a single period (treatments B, E, H vs. C, D, F, G, I, and J); 3 = added fat only during period 1 vs. added fat only during period 2 (treatments C, F, I vs. D, G, and J); 4 = tallow vs. blend (treatments B, C, D vs. E, F, and G); $5=$ blend vs. soy oil (treatments E, F, G, vs. H, I, and J); and 6 = tallow vs. soy oil (treatments B, C, D, vs. H, I, and J).

${ }^{7} \mathrm{LEA}=$ loin eye area; $\mathrm{BF}=$ backfat; adjusted using $\mathrm{HCW}$ as a covariate.

${ }^{8}$ FFLI $=$ fat free lean index; calculated using the National Pork Producers Council (2000) equation.

\section{Fatty Acid Composition and Iodine Value}

Backfat. The main effect of adding $4 \%$ fat increased $(P<0.05) \mathrm{C} 18: 2, \mathrm{C} 18: 3$, PUFA, and IV and decreased $(P<0.05) \mathrm{C} 16: 1, \mathrm{C} 18: 1, \mathrm{C} 20: 1$, SFA, and MUFA compared with pigs fed a control diet over both periods (Table 5). A feeding duration $\times$ fat source interaction $(P<0.05)$ was observed for C18:1, C18:2, C18:3, SFA, MUFA, PUFA, and IV for pigs fed tallow vs. soybean oil and for C18:2, C18:3, C20:1, MUFA, PUFA, and IV for the blend of soybean oil and tallow vs. soybean oil. In both of these interactions, MUFA was decreased and PUFA was increased by the addition of soybean oil whereas the values were relatively unchanged by the addition of tallow or a blend of the 2 . A feeding duration $\times$ fat source (tallow vs. the blend of soybean oil and tallow $)$ interaction $(P<0.05)$ was also observed for C18:2, C18:3, PUFA, and IV, as those were increased to a greater extent by the blend of soybean oil and tallow vs. tallow alone. The duration of feeding tallow did not impact IV (Fig. 1, panel A), whereas the increased duration of feeding the blend diet (Fig. 1, panel B) increased backfat IV $7.2 \mathrm{~g} / 100 \mathrm{~g}$ compared with those fed tallow. Feeding soybean oil (Fig. 1, panel C) for the increased duration of $84 \mathrm{~d}$ also increased backfat IV by $15.4 \mathrm{~g} / 100 \mathrm{~g}$ when compared with pigs fed tallow.

Feeding period $\times$ fat source interactions $(P<0.05)$ were observed for C18:2, C18:3, MUFA, PUFA, and 
Table 5. Effects of source and duration of feeding fat on backfat quality of finishing pigs ${ }^{1,2}$

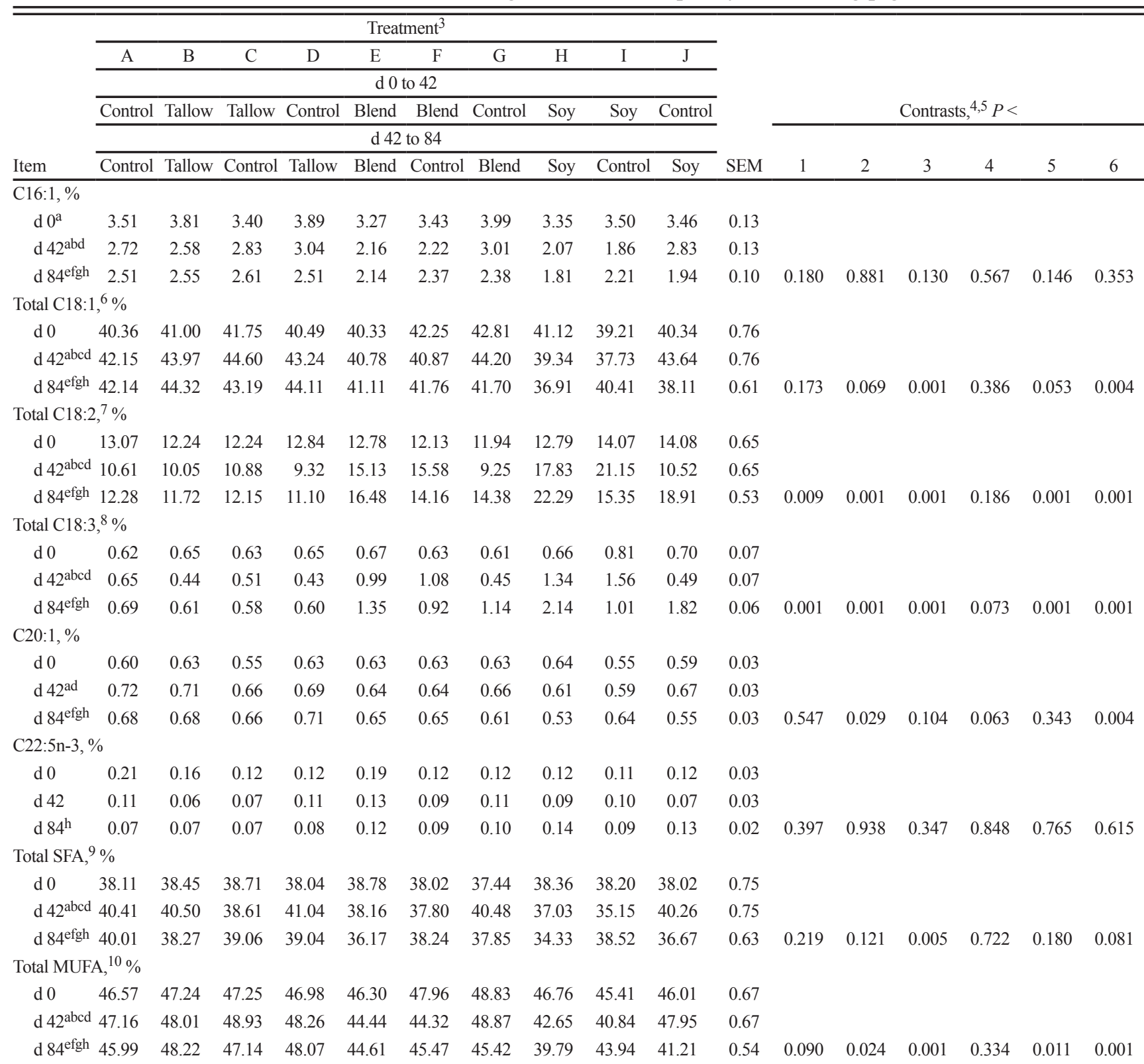

(Continued)

IV for pigs fed the blend of soybean oil and tallow vs. soybean oil and tallow vs. soybean oil. For tallow vs. soybean oil, the interaction $(P<0.05)$ also occurred for $\mathrm{C} 18: 1$ and $\mathrm{C} 20: 1$. These interactions were a result of pigs fed soybean oil from d 42 to 84 having a greater increase in PUFA and reduction in MUFA on $\mathrm{d} 84$, which increased IV by $6 \mathrm{~g} / 100 \mathrm{~g}$ when compared with pigs fed soybean oil from d 0 to 42 , whereas feeding tallow or the blend of soybean oil and tallow had relatively similar values for d-84 MUFA, PUFA, and IV, regardless of the period fed. For pigs fed the control diet from d 0 to 42 and then added fat from d 42 to 84 , tallow or the blend of soybean oil and tallow reduced backfat IV by 8.9 and $3.9 \mathrm{~g} / 100 \mathrm{~g}$, respectively, compared with those fed soybean oil.
No interactions were observed for C16:1 concentrations in backfat biopsies; however, feeding tallow did increase $(P<0.05)$ the fatty acid concentration level in the fat depot for $\mathrm{d} 42$ and 84 compared with pigs fed the blend of soybean oil and tallow as well as those fed soybean oil. Also for d 84, pigs fed the blend of soybean oil and tallow had increased $(P<0.05)$ concentrations of C16:1 in comparison with pigs fed soybean oil. C22:5n-3 concentrations were increased $(P<0.05)$ on $\mathrm{d} 84$ for pigs fed soybean oil compared with pigs fed tallow.

Belly Fat. Adding 4\% fat increased $(P<0.05)$ C18:2, C18:3, PUFA, and IV and decreased $(P<0.05) \mathrm{C} 16: 1$, C18:1, SFA, and MUFA for both period 1 and 2 compared with control pigs (Table 6). In addition, C20:1 was decreased $(P<0.05)$ on d 84 when $4 \%$ fat was added 
Table 5. (cont.)

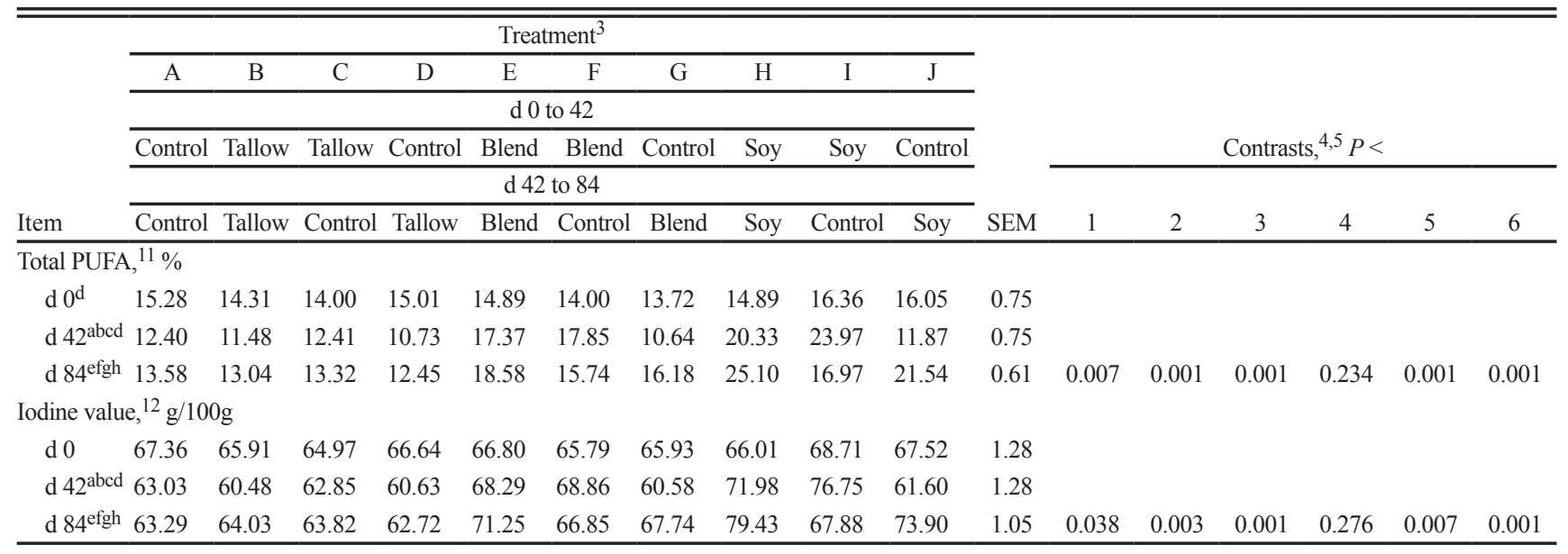

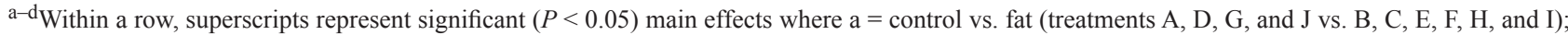
$\mathrm{b}=$ tallow vs. blend (treatments B and C vs. E and F); $\mathrm{c}=$ blend vs. soy oil (treatments E and F vs. H and I); and d = tallow vs. soy oil (treatments B and C vs. $\mathrm{H}$ and I).

e-hWithin a row, superscripts represent significant $(P<0.05)$ main effects where e = control vs. fat (treatments A, C, F, and I vs. B, D, E, G, H, and J); $\mathrm{f}=$ tallow vs. blend (treatments B and D vs. E and G); $\mathrm{g}=$ blend vs. soy oil (treatments $\mathrm{E}$ and $\mathrm{G}$ vs. $\mathrm{H}$ and $\mathrm{J}$ ); and $\mathrm{h}=$ tallow vs. soy oil (treatments B and D vs. $\mathrm{H}$ and $\mathrm{J}$ ).

${ }^{1} \mathrm{~A}$ total of 160 finishing pigs (PIC $337 \times 1050$; initial BW of $45.6 \mathrm{~kg}$ ) were used in an 84-d finishing trial with 2 pigs per pen and 8 pens per treatment. ${ }^{2} \mathrm{C} 22: 6 n-3$ not included; all values were equal to or less than 0.003 .

${ }^{3}$ Control $=$ corn soybean meal diet with no fat; Tallow $=4 \%$ beef tallow; Blend $=2 \%$ tallow and $2 \%$ soybean oil; Soy $=4 \%$ soybean oil.

${ }^{4}$ There was a treatment $\times$ day interaction $(P<0.001)$ for all variables except $\mathrm{C} 22: 5 n-3(P=0.3066)$.

${ }^{5}$ The d- 84 contrast statements for interactions are as follows: $1=$ feeding duration $(84$ vs. $42 \mathrm{~d}) \times$ fat source (tallow vs. blend); $2=$ feeding duration $(84$ vs. $42 \mathrm{~d}$ ) $\times$ fat source (blend vs. soy oil); $3=$ feeding duration $(84$ vs. $42 \mathrm{~d}$ ) $\times$ fat source (tallow vs. soy oil); $4=$ feeding period $(\mathrm{d} 0$ to 42 vs. $\mathrm{d} 42$ to 84$) \times$ fat source (tallow vs. blend); 5 = feeding period (d 0 to 42 vs. $\mathrm{d} 42$ to 84 ) $\times$ fat source (blend vs. soy oil); and $6=$ feeding period (d 0 to 42 vs. $\mathrm{d} 42$ to 84 ) $\times$ fat source (tallow vs. soy oil).

${ }^{6}$ Total C18:1 $=([\mathrm{C} 18: 1 n-9 t]+[\mathrm{C} 18: 1 n-11 t]+[\mathrm{C} 18: 1 n-9 c]+[\mathrm{C} 18: 1 n-11 c]) ;$ brackets indicate concentration.

${ }^{7}$ Total C18:2 $\left.=([\mathrm{C} 18: 2 n-6 t]+\mathrm{C} 18: 2 n-6 c]\right) ;$ brackets indicate concentration.

${ }^{8}$ Total $\mathrm{C} 18: 3=([\mathrm{C} 18: 3 n-6]+[\mathrm{C} 18: 3 n-3]) ;$ brackets indicate concentration.

${ }^{9} \mathrm{Total} \mathrm{SFA}=([\mathrm{C} 6: 0]+[\mathrm{C} 8: 0]+[\mathrm{C} 10: 0]+[\mathrm{C} 11: 0]+[\mathrm{C} 12: 0]+[\mathrm{C} 14: 0]+[\mathrm{C} 15: 0]+[\mathrm{C} 16: 0]+[\mathrm{C} 17: 0]+[\mathrm{C} 18: 0]+[\mathrm{C} 20: 0]+[\mathrm{C} 21: 0]+[\mathrm{C} 22: 0]+$ $[\mathrm{C} 23: 0]+[\mathrm{C} 24: 0])$; brackets indicate concentration.

${ }^{10}$ Total MUFA $=([\mathrm{C} 14: 1]+[\mathrm{C} 16: 1]+[\mathrm{C} 17: 1]+[\mathrm{C} 18: 1 n-9 t]+[\mathrm{C} 18: 1 n-11 t]+[\mathrm{C} 18: 1 n-9 c]+[\mathrm{C} 18: 1 n-11 c]+[\mathrm{C} 20: 1]+[\mathrm{C} 22: 1 n-9]+[\mathrm{C} 24: 1]) ;$ brackets indicate concentration.

${ }^{11}$ Total PUFA $=([\mathrm{C} 18: 2 n-6 t]+[\mathrm{C} 18: 2 n-6 c]+[\mathrm{C} 18: 3 n-6]+[\mathrm{C} 18: 3 n-3]+[$ CLA 9c11t] $+[$ CLA 10t12c] $+[$ CLA 9c11c] $+[$ CLA 9t11t] $+[$ C20:2] + $[\mathrm{C} 20: 3 n-6]+[\mathrm{C} 20: 3 n-3]+[\mathrm{C} 22: 2]+[\mathrm{C} 20: 5 n-3]+[\mathrm{C} 22: 5 n-3]+[\mathrm{C} 22: 6 n-3]) ;$ brackets indicate concentration.

${ }^{12}$ Calculated as iodine value $\left.=[\mathrm{C} 16: 1] \times 0.9502+[\mathrm{C} 18: 1] \times 0.8598+[\mathrm{C} 18: 2] \times 1.7315\right]+[\mathrm{C} 18: 3] \times 2.6125+[\mathrm{C} 20: 1] \times 0.7852+[\mathrm{C} 22: 1 n-9] \times$ $3.2008+[\mathrm{C} 22: 5 n-3] \times 3.6974+[\mathrm{C} 22: 6 n-3] \times 4.4632$; brackets indicate concentrations.

compared with pigs fed the control diet, which contained no added fat. Feeding duration $\times$ fat source interactions $(P<0.05)$ were observed for pigs fed soybean oil vs. tallow for C18:1, C18:2, C18:3, SFA, MUFA, PUFA, and IV. A feeding duration $\times$ fat source interaction $(P<0.05)$ was also observed for C18:2, C18:3, PUFA, and IV for pigs fed soybean oil vs. the blend of soybean oil and tallow. Furthermore, feeding duration $\times$ fat source interactions $(P<0.05)$ for tallow vs. the blend of soybean oil and tallow for C18:2, C18:3, and PUFA were observed, and there was also a tendency $(P=0.081)$ for IV. These interactions were a result of feeding duration not affecting IV for pigs fed tallow (Fig. 2, panel A) whereas the increased duration from 42 to $84 \mathrm{~d}$ increased IV by 2.54 $\mathrm{g} / 100 \mathrm{~g}$ for pigs fed the blend of tallow and soybean oil (Fig. 2, panel B) and $6.15 \mathrm{~g} / 100 \mathrm{~g}$ for those fed soybean oil (Fig. 2, panel C). Furthermore, interactions were a result of elevated levels of PUFA and reduced levels of SFA and MUFA with increasing feeding duration of soybean oil relative to other fat sources.

A feeding period $\times$ fat source (tallow vs. soybean oil) interaction $(P<0.05)$ was observed for C18:1, C18:2, C18:3, C20:1, MUFA, PUFA, and IV. These were driven by the decrease of MUFA levels and the increased PUFA levels in pigs fed soybean oil relative to pigs fed tallow. There was a feeding period $\times$ fat source (soybean oil vs. the blend of soybean oil and tallow) interaction $(P<0.05)$ observed for C18:2, C18:3, PUFA, and IV, which again was found by the increased concentrations in pigs fed soybean oil. Pigs fed the blend of soybean oil and tallow had a greater increase in C18:3 than those fed tallow (feeding period $\times$ fat source, $P$ $<0.05$ ). These interactions are better illustrated for IV, as pigs fed either tallow or a blend of soybean oil 


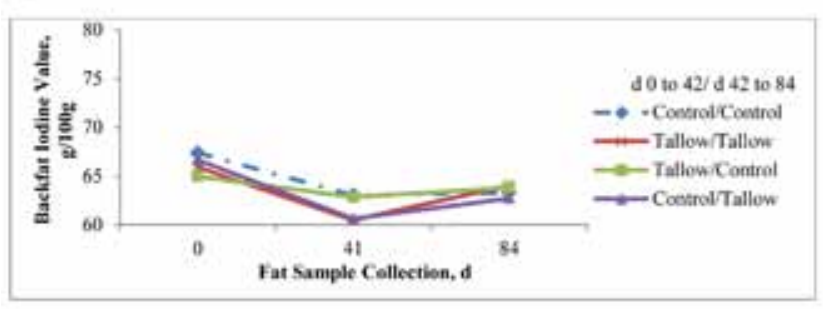

B

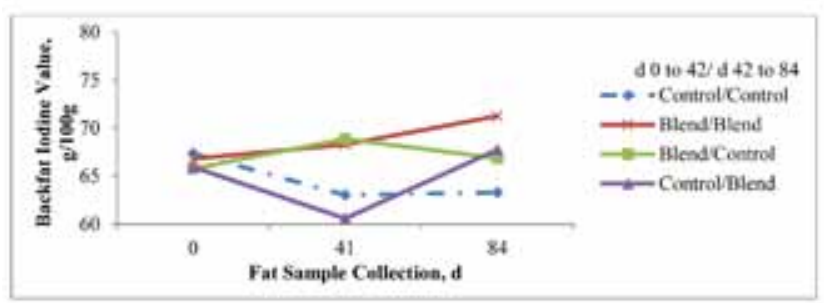

C

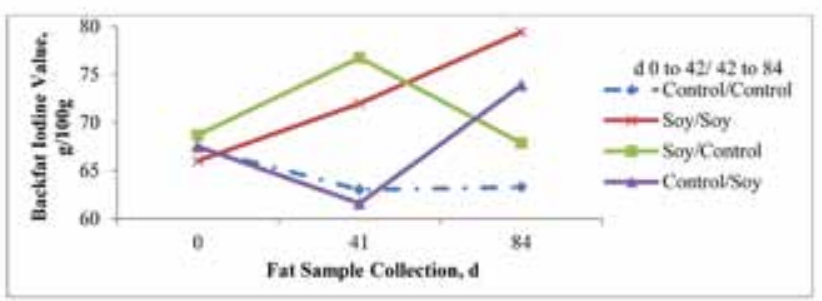

Figure 1. Effect of feeding duration of added fat on backfat iodine value (IV). A total of 160 finishing pigs (PIC $337 \times 1050$; initial BW of $45.6 \mathrm{~kg}$ ) were used in an 84-d finishing trial with 2 pigs per pen and 8 pens per treatment. Values represent the mean of 8 pigs per treatment, representing 1 pig per pen. Fat was added to the diet during period 1 ( $\mathrm{d} 0$ to 42), period 2 (d 42 to 84), or the duration of the study (d 0 to 84). Biopsy samples were taken on d 0,41 , and 84 for analysis. (A) Effects of $4 \%$ tallow on backfat IV. (B) Effects of 2\% soybean oil and 2\% tallow on backfat IV. (C) Effects of $4 \%$ soybean oil on backfat IV.

and tallow for only a single period (either 1 or 2) were observed to have very similar belly fat IV on $\mathrm{d} 84$. However, those fed soybean oil from d 42 to 84 had a $3.62 \mathrm{~g} / 100 \mathrm{~g}$ greater belly fat IV than those fed soybean oil from d 0 to 42 . Therefore, the turnover observed in pigs fed a highly unsaturated fat source compared with pigs fed a more saturated fat source not having any differences among period drove the interaction.

Although no interactions were observed, feeding tallow during either period increased $(P<0.05)$ C16:1 concentrations in belly fat compared with pigs fed soybean oil or the blend of soybean oil and tallow. Additionally, C22:5n-3 concentration was increased $(P<0.05)$ for both period 1 and 2 when pigs were fed soybean oil compared with tallow. Similarly, pigs fed the blend of soybean oil and tallow during period 1 had increased $(P<0.05)$ C22:5n-3 concentrations when compared with those fed tallow.

Jowl Fat. Adding 4\% fat increased $(P<0.05) \mathrm{C} 18: 2$, C18:3, C22:5n-3, PUFA, and IV and decreased $(P<$ 0.05) C16:1, SFA, and MUFA on both d 42 and 84 and
A

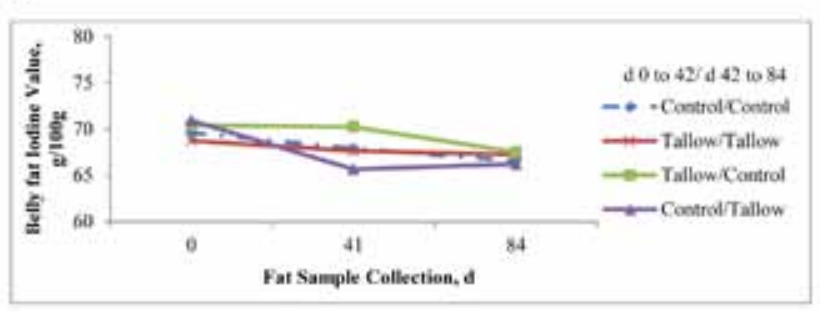

B

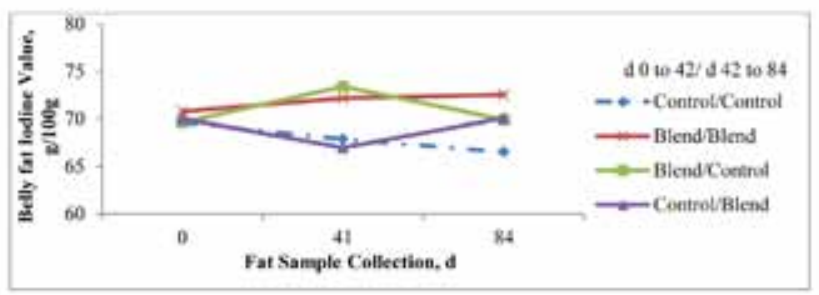

C

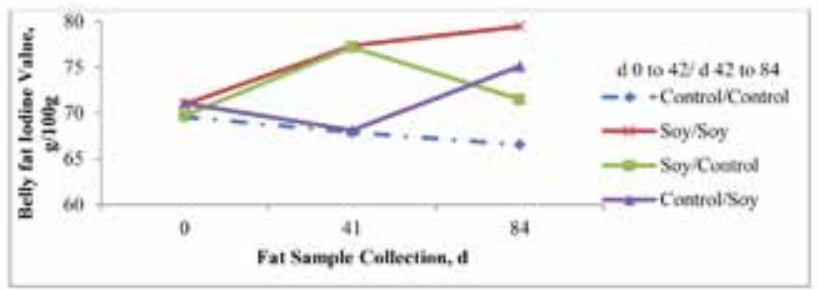

Figure 2. Effect of feeding duration of added fat on belly iodine value (IV). A total of 160 finishing pigs (PIC $337 \times 1050$; initial BW of $100.5 \mathrm{~kg}$ ) were used in an 84-d finishing trial with 2 pigs per pen and 8 pens per treatment. Values represent the mean of 8 pigs per treatment, representing 1 pig per pen. Fat was added to the diet during period 1 (d 0 to 42 ), period 2 (d 42 to 84 ), or the duration of the study ( 0 to 84 ). Biopsy samples were taken on d 0,41 , and 84 for analysis. (A) Effects of 4\% tallow on belly IV. (B) Effects of 2\% soybean oil and $2 \%$ tallow on belly IV. (C) Effects of $4 \%$ soybean oil on belly IV.

decreased $(P<0.05)$ total $\mathrm{C} 18: 1$ on $\mathrm{d} 42$ compared with pigs fed the control diet (Table 7). There was a feeding duration $\times$ fat source interaction $(P<0.05)$ among pigs fed tallow vs. soybean oil for C18:2, C18:3, C22:5n-3, SFA, MUFA, PUFA, and IV. A feeding duration $\times$ fat source interaction $(P<0.05)$ was also observed for the blend of soybean oil and tallow vs. soybean oil for C18:2, C18:3, C20:1, PUFA, and IV. These interactions were driven by the elevated levels of PUFA and reduced levels of MUFA and SFA with increasing feeding duration for soybean oil relative to other fat sources. A feeding duration $\times$ fat source (tallow vs. blend) interaction $(P=$ $0.001)$ was observed for $\mathrm{C} 18: 3$ as well as a tendency $(P<$ 0.10 ) for C18:2, PUFA, and IV. The IV interactions were a result of the duration of feeding tallow (Fig. 3, panel A) not impacting IV, whereas the increased duration of feeding soybean oil and tallow (Fig. 3, panel B) or soybean oil (Fig. 3, panel C) increased jowl fat IV by 4.7 and $10.8 \mathrm{~g} / 100 \mathrm{~g}$, respectively, compared with those fed tallow.

For C18:3, feeding period $\times$ fat source interactions $(P<0.05)$ for the blend of soybean oil and tallow vs. soybean oil alone and tallow vs. soybean oil were observed 
Table 6. Effects of source and duration of added fat on belly fat quality of finishing pigs ${ }^{1,2}$

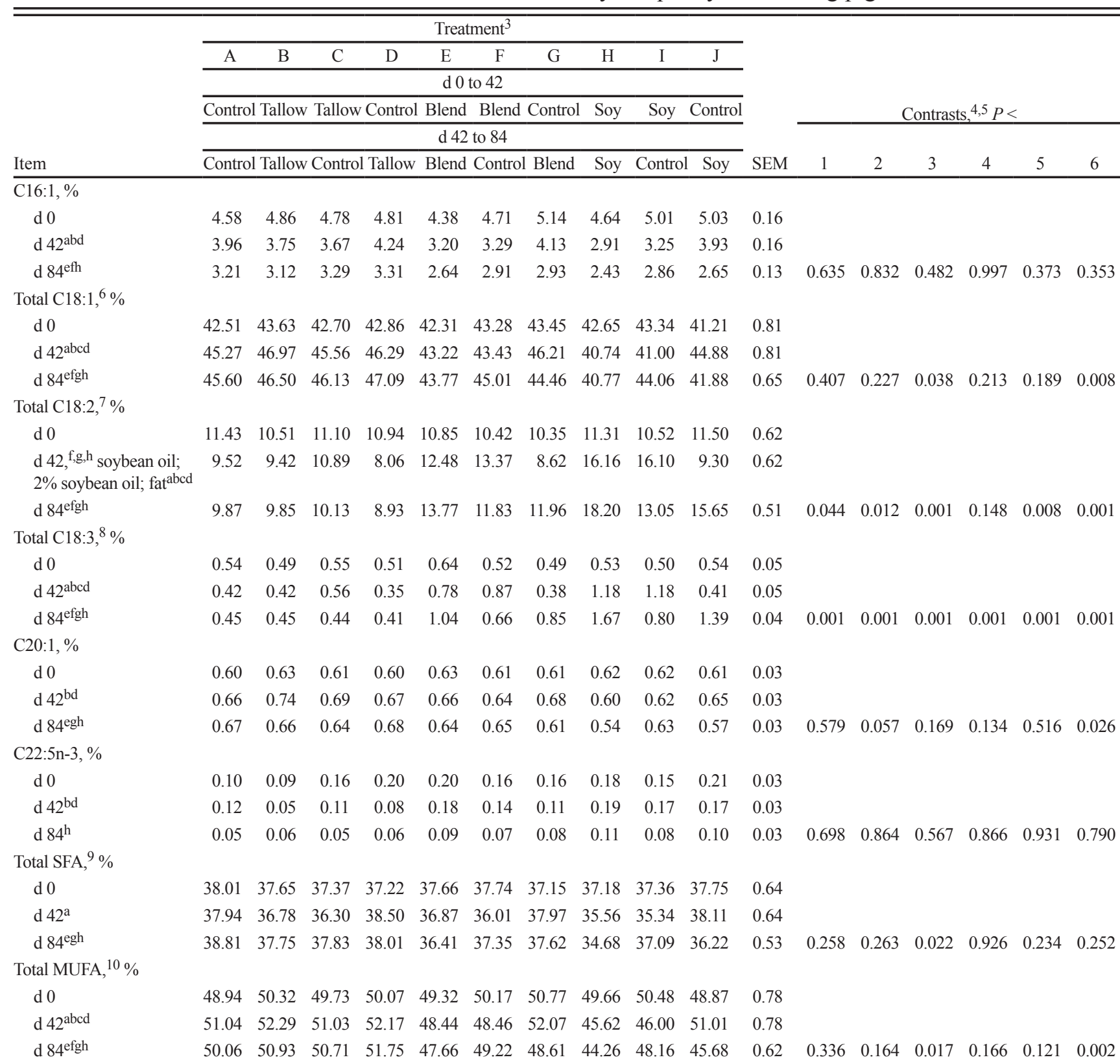

(Continued)

as well as a tendency $(P<0.10)$ for an interaction for tallow vs. the blend of soybean oil and tallow. This was caused by the greater increase in $\mathrm{C} 18: 3$ concentration in pigs fed soybean oil relative to tallow or the blend of soybean oil and tallow. Pigs fed tallow had a greater increase in C20:1 than pigs fed soybean oil (feeding period $\times$ fat source, $P<0.05)$. No feeding period $\times$ fat source interactions $(P<0.05)$ were observed for IV. This is due to the similar IV reported on d 84 within each fat source for pigs fed added fat for a single period, which is unlike the other fat depots evaluated in this study.

No interactions were observed for the fatty acids C16:1 and C18:1; however, concentrations for each of these fatty acids were increased $(P<0.05)$ in pigs fed tallow compared with pigs fed soybean oil for both periods 1 and 2. Additionally, C18:1 concentration was increased $(P<0.05)$ in pigs fed tallow compared with those fed either soybean oil or the blend of soybean oil and tallow in both periods.

\section{DISCUSSION}

Numerous studies have shown that adding fat to swine diets in some or all of the finishing phase improves feed efficiency when compared with pigs fed a diet without fat (Weber et al., 2006; Benz et al., 2011a; Kellner et al., 2014). The increase in ADG from $\mathrm{d} 0$ to 42 for pigs fed added fat in the current study agrees with 
Table 6. (cont.)

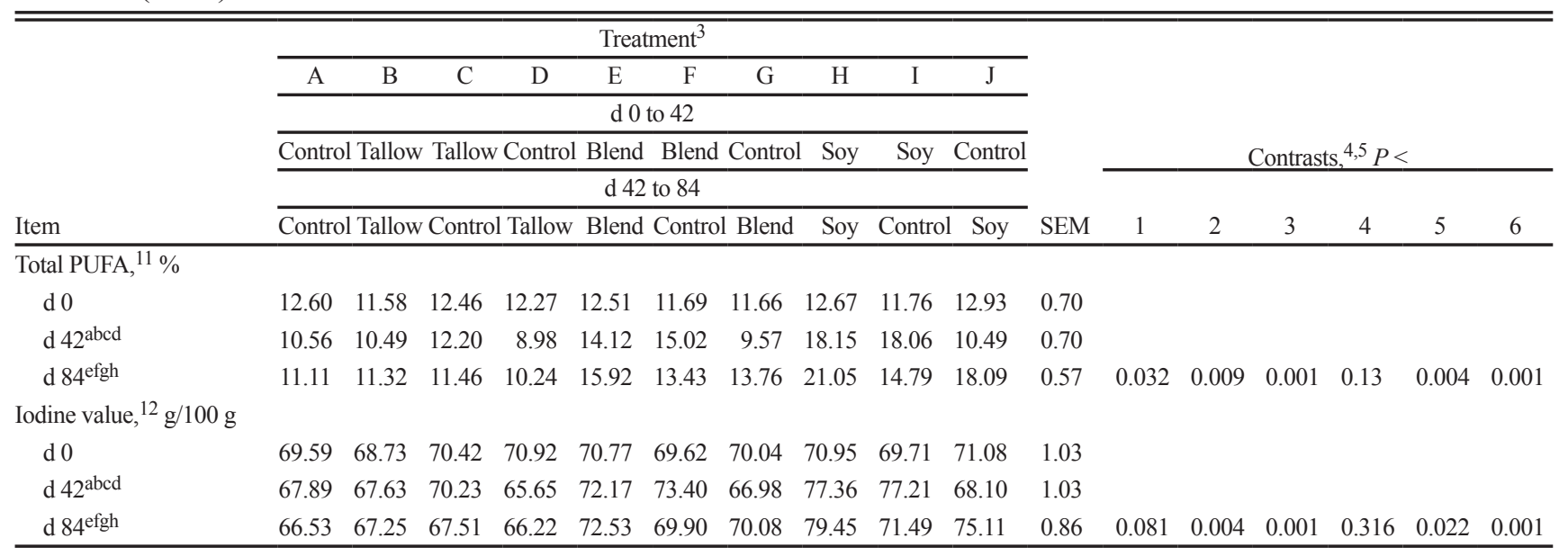

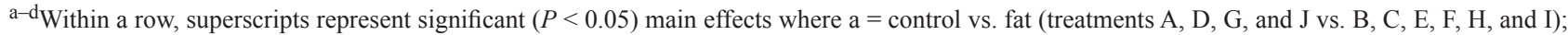
$\mathrm{b}=$ tallow vs. blend (treatments B and C vs. E and F); $\mathrm{c}=$ blend vs. soy oil (treatments $\mathrm{E}$ and $\mathrm{F}$ vs. $\mathrm{H}$ and I); and $\mathrm{d}=$ tallow vs. soy oil (treatments B and C vs. H and I).

e-hWithin a row, superscripts represent significant $(P<0.05)$ main effects where e = control vs. fat (treatments A, C, F, and I vs. B, D, E, G, H, and J); $\mathrm{f}=$ tallow vs. blend (treatments $\mathrm{B}$ and $\mathrm{D}$ vs. $\mathrm{E}$ and $\mathrm{G}$ ); $\mathrm{g}=$ blend vs. soy oil (treatments $\mathrm{E}$ and $\mathrm{G}$ vs. $\mathrm{H}$ and $\mathrm{J}$ ); and $\mathrm{h}=$ tallow vs. soy oil (treatments $\mathrm{B}$ and D vs. $\mathrm{H}$ and $\mathrm{J})$.

${ }^{1} \mathrm{~A}$ total of 160 finishing pigs (PIC $337 \times 1050$; initial BW of $45.6 \mathrm{~kg}$ ) were used in an $84-\mathrm{d}$ finishing trial with 2 pigs per pen and 8 pens per treatment. ${ }^{2} \mathrm{C} 22: 6 n-3$ not included; all values were equal to or less than 0.003 .

${ }^{3}$ Control $=$ corn soybean meal diet with no fat; Tallow $=4 \%$ beef tallow; Blend $=2 \%$ tallow and $2 \%$ soybean oil; Soy $=4 \%$ soybean oil.

${ }^{4}$ There was a treatment $\times$ day interaction $(P<0.001)$ for all variables except $\mathrm{C} 20: 1(P=0.004)$ and $\mathrm{C} 22: 5 n-3(P=0.7639)$.

${ }^{5}$ The d- 84 contrast statements for interactions are as follows: $1=$ feeding duration $(84$ vs. $42 \mathrm{~d}) \times$ fat source (tallow vs. blend); $2=$ feeding duration $(84$ vs. $42 \mathrm{~d}$ ) $\times$ fat source (blend vs. soy oil); $3=$ feeding duration $(84$ vs. $42 \mathrm{~d}$ ) $\times$ fat source (tallow vs. soy oil); $4=$ feeding period $(\mathrm{d} 0$ to 42 vs. $\mathrm{d} 42$ to 84$) \times$ fat source (tallow vs. blend); 5 = feeding period (d 0 to 42 vs. $\mathrm{d} 42$ to 84 ) $\times$ fat source (blend vs. soy oil); and $6=$ feeding period (d 0 to 42 vs. $\mathrm{d} 42$ to 84$) \times$ fat source (tallow vs. soy oil).

${ }^{6}$ Total C18:1 $=([\mathrm{C} 18: 1 n-9 t]+[\mathrm{C} 18: 1 n-11 t]+[\mathrm{C} 18: 1 n-9 c]+[\mathrm{C} 18: 1 n-11 c]) ;$ brackets indicate concentration.

${ }^{7}$ Total $\left.\mathrm{C} 18: 2=([\mathrm{C} 18: 2 n-6 t]+\mathrm{C} 18: 2 n-6 c]\right) ;$ brackets indicate concentration.

${ }^{8}$ Total $\mathrm{C} 18: 3=([\mathrm{C} 18: 3 n-6]+[\mathrm{C} 18: 3 n-3]) ;$ brackets indicate concentration.

${ }^{9} \mathrm{Total} \mathrm{SFA}=([\mathrm{C} 6: 0]+[\mathrm{C} 8: 0]+[\mathrm{C} 10: 0]+[\mathrm{C} 11: 0]+[\mathrm{C} 12: 0]+[\mathrm{C} 14: 0]+[\mathrm{C} 15: 0]+[\mathrm{C} 16: 0]+[\mathrm{C} 17: 0]+[\mathrm{C} 18: 0]+[\mathrm{C} 20: 0]+[\mathrm{C} 21: 0]+[\mathrm{C} 22: 0]+$ $[\mathrm{C} 23: 0]+[\mathrm{C} 24: 0]) ;$ brackets indicate concentration.

${ }^{10}$ Total MUFA $=([\mathrm{C} 14: 1]+[\mathrm{C} 16: 1]+[\mathrm{C} 17: 1]+[\mathrm{C} 18: 1 n-9 t]+[\mathrm{C} 18: 1 n-11 t]+[\mathrm{C} 18: 1 n-9 c]+[\mathrm{C} 18: 1 n-11 c]+[\mathrm{C} 20: 1]+[\mathrm{C} 22: 1 n-9]+[\mathrm{C} 24: 1]) ;$ brackets indicate concentration.

${ }^{11}$ Total PUFA $=([\mathrm{C} 18: 2 n-6 t]+[\mathrm{C} 18: 2 n-6 c]+[\mathrm{C} 18: 3 n-6]+[\mathrm{C} 18: 3 n-3]+[$ CLA 9c11t] $+[$ CLA 10t12c] $+[$ CLA 9c11c] $+[$ CLA 9t11t] $+[$ C $20: 2]$ $[\mathrm{C} 20: 3 n-6]+[\mathrm{C} 20: 3 n-3]+[\mathrm{C} 22: 2]+[\mathrm{C} 20: 5 n-3]+[\mathrm{C} 22: 5 n-3]+[\mathrm{C} 22: 6 n-3]) ;$ brackets indicate concentration.

${ }^{12}$ Calculated as iodine value $\left.=[\mathrm{C} 16: 1] \times 0.9502+[\mathrm{C} 18: 1] \times 0.8598+[\mathrm{C} 18: 2] \times 1.7315\right]+[\mathrm{C} 18: 3] \times 2.6125+[\mathrm{C} 20: 1] \times 0.7852+[\mathrm{C} 22: 1 n-9] \times$ $3.2008+[\mathrm{C} 22: 5 n-3] \times 3.6974+[\mathrm{C} 22: 6 n-3] \times 4.4632$; brackets indicate concentrations.

results from Campbell and Taverner (1988) and De la Llata et al. (2001), indicating pigs were in an energydependent state for this period of growth as described by Pettigrew and Esnaola (2001). By adding dietary fat, more energy was provided in the feed, which allowed pigs to increase protein accretion when compared with pigs that were not fed an additional fat source in this early stage of growth. Data from De la Llata et al. (2001) would suggest that in the late finishing stage, adding fat will generally elicit an improvement in ADG when pigs are housed in a commercial facility ( $>20$ pigs per pen) vs. those housed in small pens in typical university research settings. Despite the current study being performed in a university research setting, a tendency for improved ADG was also observed for pigs fed added fat in the final $42 \mathrm{~d}$. There was no difference in ADG when adding fat throughout the entire finishing period, which agrees with data from Weber et al. (2006) and Apple et al. (2009b). The lack of response in overall growth to adding fat was partly due to the fact that there were fewer treatments in the overall fat response comparison ( 3 treatments) than in either period 1 or 2 (6 treatments).

Results from Apple et al. (2009b), Lee et al. (2013), and Kellner et al. (2014) show no ADFI response when comparing added-fat diets with those without additional fat, which would agree with results from the current research. However, some have observed reductions in ADFI when feeding additional fat compared with feeding a diet without added fat (De la Llata et al. (2001) and Eggert et al., 2007).

Added dietary fat has been shown to improve HCW and carcass yield (Smith et al., 1999; Jackson et al., 2009), whereas others have shown no affect, which would agree with findings from the present study (Bee et al., 2002; 
Table 7. Effects of source and duration of added fat on jowl fat quality of finishing pigs ${ }^{1,2}$

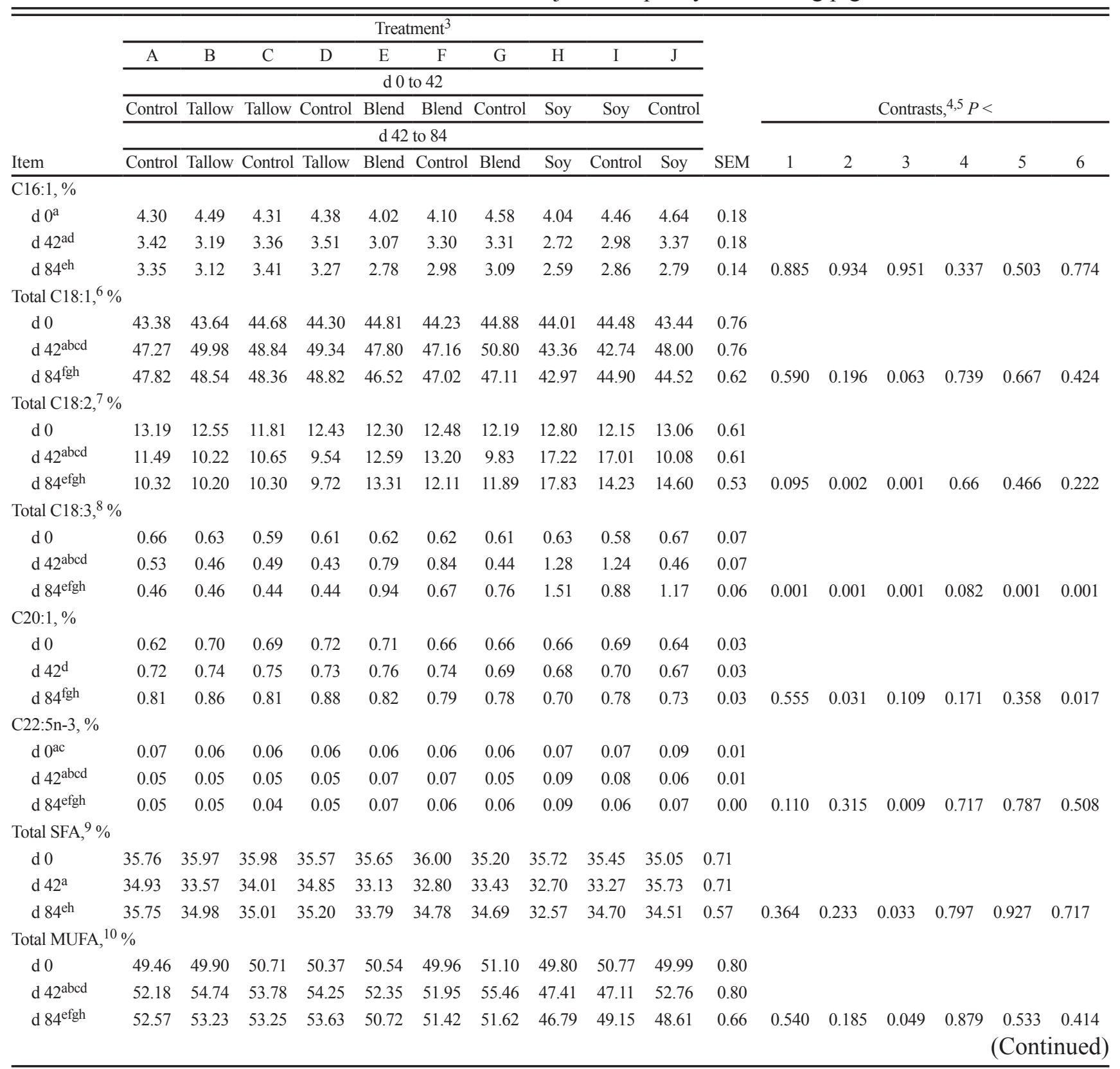

Apple et al., 2009b; Coble et al., 2015). However, added fat did increase backfat depth. Similarly, Apple et al. (2009b) and Benz et al. (2011b) reported that carcasses from pigs fed added dietary fat, regardless of source, had greater average backfat depths than carcasses from pigs fed a diet without added fat. This would be expected as the pig is consuming a high energy diet and once the pig has reached the break point of protein accretion, they will rapidly fatten (Pettigrew and Esnaola, 2001).

Several feeding duration $\times$ fat source interactions were observed in the study herein. The feeding duration $x$ fat source interactions for tallow vs. soybean oil and soybean oil vs. the blend of soybean oil and tallow were a result of elevated levels of PUFA and reduced MFA and SFA due to feeding soybean oil, which has a higher un- saturated fatty acid content compared with tallow. When comparing soybean oil vs. the blend of soybean oil and tallow, they both behaved similarly; however, interactions of feeding duration $\times$ fat source and feeding period $x$ fat source were caused by the greater magnitude of change in the fatty acid profile caused by feeding only soybean oil. Feeding period $\times$ fat source interactions for tallow vs. soybean oil or the blend of soybean oil and tallow were observed due to the relatively consistent response throughout feeding by pigs fed tallow for a single period and the inverse responses observed by pigs fed soybean oil or the blend of soybean oil and tallow for a single period that are then fed a control diet. This would be consistent with results from Apple et al. (2009b), as the authors observed that feeding beef tallow increased 
Table 7. (cont.)

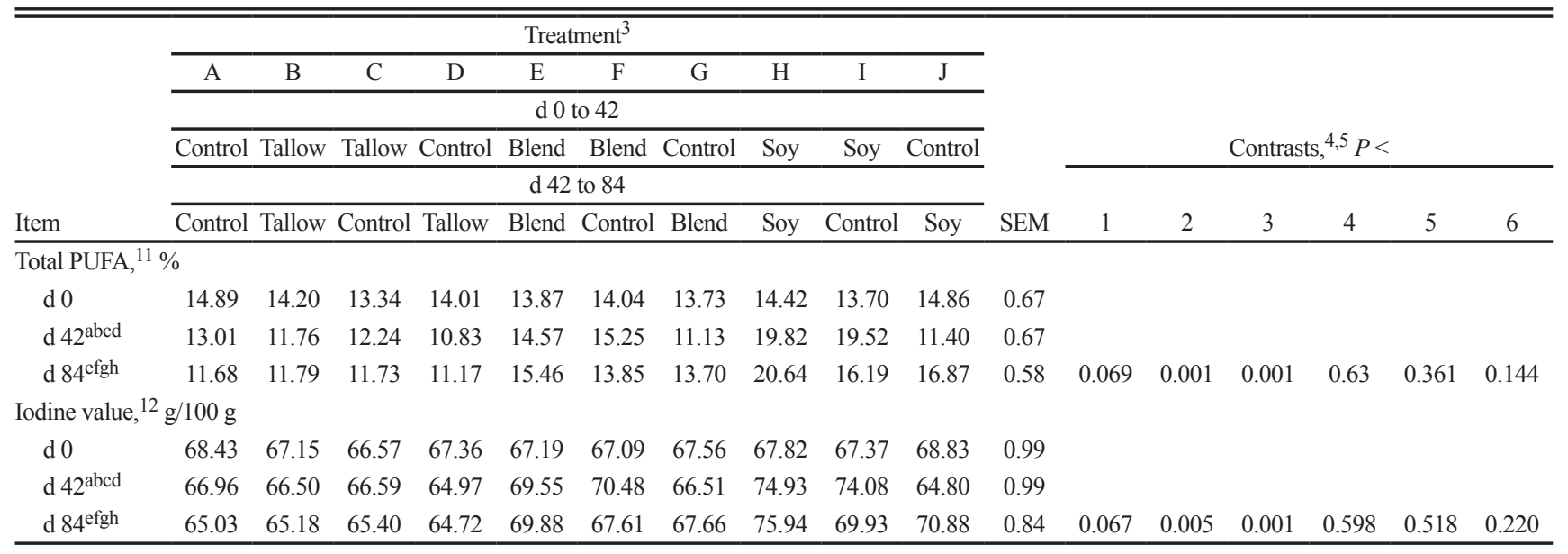

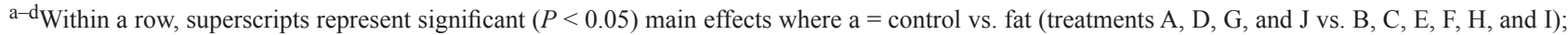
$\mathrm{b}=$ tallow vs. blend (treatments B and C vs. E and F); $\mathrm{c}=$ blend vs. soy oil (treatments $\mathrm{E}$ and $\mathrm{F}$ vs. $\mathrm{H}$ and I); and $\mathrm{d}=$ tallow vs. soy oil (treatments B and C vs. H and I).

e-hWithin a row, superscripts represent significant $(P<0.05)$ main effects where e = control vs. fat (treatments A, C, F, and I vs. B, D, E, G, H, and J); $\mathrm{f}=$ tallow vs. blend (treatments B and D vs. E and G); $\mathrm{g}=$ blend vs. soy oil (treatments $\mathrm{E}$ and $\mathrm{G}$ vs. $\mathrm{H}$ and $\mathrm{J}$ ); and $\mathrm{h}=$ tallow vs. soy oil (treatments B and D vs. $\mathrm{H}$ and $\mathrm{J})$.

${ }^{1} \mathrm{~A}$ total of 160 finishing pigs (PIC $337 \times 1050$; initial BW of $45.6 \mathrm{~kg}$ ) were used in an $84-\mathrm{d}$ finishing trial with 2 pigs per pen and 8 pens per treatment. ${ }^{2} \mathrm{C} 22: 6 n-3$ not included; all values were equal to or less than 0.01 .

${ }^{3}$ Control $=$ no added fat; Tallow $=4 \%$ beef tallow; Soy $=4 \%$ soybean oil; Blend $=2 \%$ tallow and $2 \%$ soybean oil

${ }^{4}$ There was a treatment $\times$ day interaction $(P<0.001)$ for all variables except $\mathrm{C} 16: 1(P=0.1233), \mathrm{C} 20: 1(P=0.0326)$, and saturated fatty acids $(P=0.074)$.

${ }^{5}$ The d-84 contrast statements for interactions are as follows: $1=$ feeding duration $(84$ vs. $42 \mathrm{~d}) \times$ fat source (tallow vs. blend); $2=$ feeding duration $(84$ vs. $42 \mathrm{~d}$ ) $\times$ fat source (blend vs. soy oil); $3=$ feeding duration $(84$ vs. $42 \mathrm{~d}$ ) $\times$ fat source (tallow vs. soy oil); $4=$ feeding period (d 0 to 42 vs. $d 42$ to 84$) \times$ fat source (tallow vs. blend); 5 = feeding period (d 0 to 42 vs. d 42 to 84 ) $\times$ fat source (blend vs. soy oil); and $6=$ feeding period (d 0 to 42 vs. $\mathrm{d} 42$ to 84 ) $\times$ fat source (tallow vs. soy oil).

${ }^{6}$ Total C18:1 $=([\mathrm{C} 18: 1 n-9 t]+[\mathrm{C} 18: 1 n-11 t]+[\mathrm{C} 18: 1 n-9 c]+[\mathrm{C} 18: 1 n-11 c]) ;$ brackets indicate concentration.

${ }^{7}$ Total C18:2 $\left.=([\mathrm{C} 18: 2 n-6 t]+\mathrm{C} 18: 2 n-6 c]\right) ;$ brackets indicate concentration.

${ }^{8}$ Total $\mathrm{C} 18: 3=([\mathrm{C} 18: 3 n-6]+[\mathrm{C} 18: 3 n-3]) ;$ brackets indicate concentration.

${ }^{9} \mathrm{Total} \mathrm{SFA}=([\mathrm{C} 6: 0]+[\mathrm{C} 8: 0]+[\mathrm{C} 10: 0]+[\mathrm{C} 11: 0]+[\mathrm{C} 12: 0]+[\mathrm{C} 14: 0]+[\mathrm{C} 15: 0]+[\mathrm{C} 16: 0]+[\mathrm{C} 17: 0]+[\mathrm{C} 18: 0]+[\mathrm{C} 20: 0]+[\mathrm{C} 21: 0]+[\mathrm{C} 22: 0]+$ $[\mathrm{C} 23: 0]+[\mathrm{C} 24: 0]) ;$ brackets indicate concentration.

${ }^{10}$ Total MUFA $=([\mathrm{C} 14: 1]+[\mathrm{C} 16: 1]+[\mathrm{C} 17: 1]+[\mathrm{C} 18: 1 n-9 t]+[\mathrm{C} 18: 1 n-11 t]+[\mathrm{C} 18: 1 n-9 c]+[\mathrm{C} 18: 1 n-11 c]+[\mathrm{C} 20: 1]+[\mathrm{C} 22: 1 n-9]+[\mathrm{C} 24: 1]) ;$ brackets indicate concentration.

${ }^{11}$ Total PUFA $=([\mathrm{C} 18: 2 n-6 t]+[\mathrm{C} 18: 2 n-6 c]+[\mathrm{C} 18: 3 n-6]+[\mathrm{C} 18: 3 n-3]+[$ CLA 9c11t] $+[$ CLA 10t12c] $+[$ CLA 9c11c] $+[$ CLA 9t11t] $+[$ C $20: 2]$ $+[\mathrm{C} 20: 3 n-6]+[\mathrm{C} 20: 3 n-3]+[\mathrm{C} 22: 2]+[\mathrm{C} 20: 5 n-3]+[\mathrm{C} 22: 5 n-3]+[\mathrm{C} 22: 6 n-3]) ;$ brackets indicate concentration.

${ }^{12}$ Calculated as iodine value $\left.=[\mathrm{C} 16: 1] \times 0.9502+[\mathrm{C} 18: 1] \times 0.8598+[\mathrm{C} 18: 2] \times 1.7315\right]+[\mathrm{C} 18: 3] \times 2.6125+[\mathrm{C} 20: 1] \times 0.7852+[\mathrm{C} 22: 1 n-9] \times 3.2008$ $+[\mathrm{C} 22: 5 n-3] \times 3.6974+[\mathrm{C} 22: 6 n-3] \times 4.4632$; brackets indicate concentrations.

MUFA levels in the LM compared with feeding soybean oil. They also observed that feeding soybean oil increased PUFA levels compared with feeding a control diet or diets with added poultry fat or beef tallow.

Browne et al. (2013a) observed changes in 18:2n6, total 18:1, MUFA, PUFA, SFA, and IV in backfat among pigs fed either beef tallow or yellow grease over a 103-d period. They found that linoleic acid and PUFA values were increased by 3.69 and 4.03 percentage units, respectively, whereas IV was increased $4.78 \mathrm{~g} / 100 \mathrm{~g}$ in pigs fed yellow grease vs. beef tallow. Similarly, Kellner et al. (2014) observed that feeding a highly unsaturated fat source (corn oil) at either 3 or $6 \%$ of the diet significantly increased IV when compared with diets with either choice white grease or beef tallow.

Recently, Paulk et al. (2015) performed a literature review to create predictive equations for back, belly, and jowl IV based on many different variables such as EFA, ADFI, and initial BW. The current study was used to validate the predictive equations and they were found to be moderately accurate for estimated backfat IV values, but they overestimate most backfat values, especially for pigs with backfat IV under $65 \mathrm{~g} / 100 \mathrm{~g}$. Belly fat IV was under predicted for most treatments, with only $34 \%$ of the variation explained by the model. This variation could be due to various collection sites used in the literature to create the equations as well as fewer total observations. Predicted jowl fat IV was highly accurate, as means were within $3.43 \mathrm{~g} / 100 \mathrm{~g}$ of actual treatment values and the model explained $72 \%$ of the variation.

To minimize the negative effects of feeding unsaturated fat sources, a withdrawal strategy can be used to improve the fatty acid profile of fat depots. When previously feeding a diet with $5 \%$ corn oil, Kellner et al. 


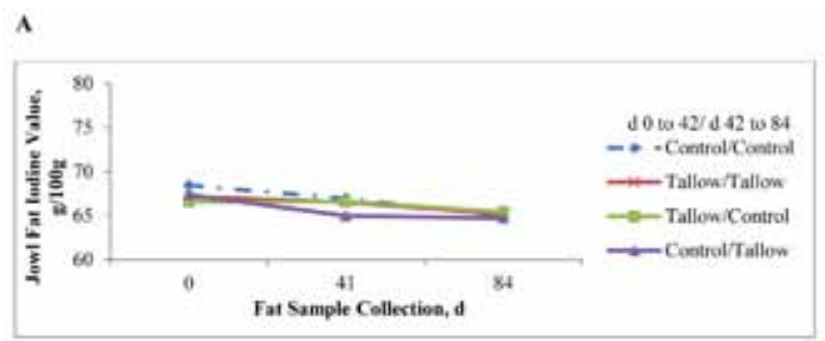

B

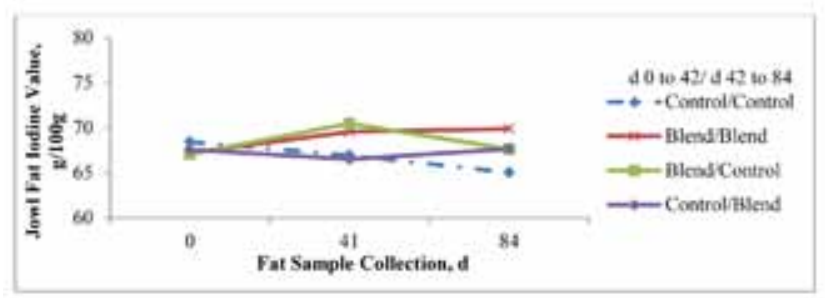

C

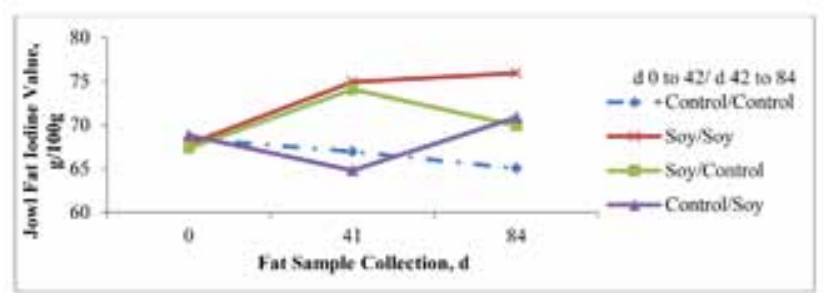

Figure 3. Effect of feeding duration of added fat on jowl iodine value (IV). A total of 160 finishing pigs (PIC $337 \times 1050$; initial BW of $100.5 \mathrm{~kg}$ ) were used in an 84 -d finishing trial with 2 pigs per pen and 8 pens per treatment. Values represent the mean of 8 pigs per treatment, representing 1 pig per pen. Fat was added to the diet during period 1 (d 0 to 42 ), period 2 (d 42 to 84 ), or the duration of the study (d 0 to 84 ). Biopsy samples were taken on d 0 , 41, and 84 for analysis. (A) Effects of 4\% tallow on jowl IV. (B) Effects of 2\% soybean oil and $2 \%$ tallow on jowl IV. (C) Effects of $4 \%$ soybean oil on jowl IV.

(2015) was able to show a similar result in jowl C18:2 percentage and IV when using a 61-d withdrawal compared with pigs fed a control diet with no added oil. However, a 40- and 19-d withdrawal still maintained a difference of 5.5 and 6.4 percentage units for $\mathrm{C} 18: 2$ as well as 5.5 and $8.7 \mathrm{~g} / 100 \mathrm{~g}$, respectively, for jowl fat when compared with pigs not fed a diet with added fat. Benz et al. (2011a) also reported that with an extended withdrawal period, a greater reduction in C18:2, PUFA, and IV can be observed in backfat and jowl fat when feeding $5 \%$ soybean oil. We observed similar responses in backfat as a 42-d withdrawal from pigs previously fed a $4 \%$ soybean oil diet resulted in 6.94 and 8.13 percentage units decrease in C18:2 and PUFA, respectively, and also lowered IV by $11.55 \mathrm{~g} / 100 \mathrm{~g}$ for backfat. As previous studies suggested, a withdrawal strategy also changed jowl fat, as C18:2 and PUFA concentrations were lower (3.6 and 4.45 percentage units, respectively) and IV was also lower by $6.01 \mathrm{~g} / 100 \mathrm{~g}$.

The current research shows little numeric changes in MUFA, PUFA, or SFA concentrations or IV when adding beef tallow in late finishing; the same cannot be said for adding 4\% soybean oil. By adding soybean oil to the diet for the final $42 \mathrm{~d}, \mathrm{C} 18: 1$ and MUFA concentrations were 5.53 and 6.74 percentage units lower, respectively, for backfat. Conversely, C18:2, PUFA, and IV values were 8.39 and 9.67 percentage units and $11.55 \mathrm{~g} / 100 \mathrm{~g}$ greater, respectively, for backfat. Adding soybean oil in late finishing also caused C18:2, PUFA, and IV values to be 4.52 and 5.47 percentage units and $6.08 \mathrm{~g} / 100 \mathrm{~g}$ greater, respectively, for jowl fat, whereas C18:1 and MUFA concentrations were 3.48 and 4.15 percentage units lower, respectively. Belly fat was similarly affected, as C18:1 and MUFA concentrations were 3 and 5.33 percentage units lower, respectively, and C18:2, PUFA, and IV values were 6.35 and 7.6 percentage units and $7.01 \mathrm{~g} / 100 \mathrm{~g}$ greater, respectively. Although these increases did not put IV over the threshold of $73 \mathrm{~g} / 100 \mathrm{~g}$ suggested by Benz et al. (2011a) for backfat or jowl fat, adding soybean oil for only the final $42 \mathrm{~d}$ did increase belly fat IV over this threshold, as it was observed to be $75.11 \mathrm{~g} / 100$ g. Work by Kellner et al. (2014) would suggest that this is directly related to the increased intake of $\mathrm{C} 18: 2$, which they found to be to be the best indicator of carcass IV.

Pigs fed tallow did not have a period effect for either backfat or belly fat in the current study with respect to IV. This could be due to the relatively low amount of linoleic acid found in beef tallow, which is one of the strongest indicators of carcass fat IV (Benz et al., 2011a; Kellner et al., 2014). Contrary to the previously discussed fat depots, jowl fat did not show a period effect in the current study. Although few publications have evaluated this specific area, Browne et al. (2013a) showed that by changing sources of fat from beef tallow to yellow grease or vice versa through the finishing phase, backfat IV can be altered, whereas in jowl fat, no differences were noted among treatments, which would indicate that there is a longer turnover rate for this particular fat depot. This could be explained by Wiegand et al. (2011), who speculated that as the fattening patterns begin from distal ends and progress toward the visceral cavity, fat would be deposited earlier in the animal's life over the jowl and later over the loin and belly, which causes the weak correlation between these fat depots. Due to the slower turnover rate, jowl fat is a poor indicator of fatty acid composition compared with belly fat or backfat and should not be used to evaluate the fatty acid composition as influenced by diet.

Increased amount of PUFA has been shown to inhibit de novo fat synthesis (Bee et al., 1999). Therefore, direct dietary fat deposition is then preferred by the animal, which increases the PUFA concentrations in pork fat depots. Increases in unsaturated fats have been correlated to decreased carcass fat quality (Widmer et al., 2008), which has been shown to present processing challenges as well as reduce shelf life (NRC, 2012). 
Results of our study show that feeding soybean oil for extended durations increases the PUFA concentration of the fat, which is consistent with Averette Gatlin (2002) and Benz et al. (2011a). By withdrawing soybean oil from the diet for the final $42 \mathrm{~d}$, the PUFA concentration can be significantly reduced in both the belly and loin fat depot. This also agrees with Benz et al. (2011a), as they removed fat from the diet for 14,28 , or $56 \mathrm{~d}$ before slaughter and showed a quadratic decrease in total PUFA concentrations for backfat as well as jowl fat, with lower concentrations correlating to longer withdrawals.

All 3 fat depots evaluated in this study maintained higher concentrations of SFA when pigs were fed beef tallow for $84 \mathrm{~d}$ compared with those fed soybean oil. This would agree with research by Bee et al. (2002), who fed pigs corn-soybean meal diets through finishing with either $5 \%$ soybean oil or $5 \%$ beef tallow and observed that pigs fed beef tallow maintained a significantly higher concentration of total SFA in carcass backfat than those fed soybean oil. Browne et al. (2013b) also showed that feeding 5\% beef tallow for $103 \mathrm{~d}$ resulted in a higher level of SFA in belly fat compared with pigs fed $4.7 \%$ yellow grease. Interestingly enough, Browne et al. (2013b) also showed that feeding beef tallow during the final 2 or 3 phases of feeding after pigs had previously been fed yellow grease resulted in nearly equivalent SFA levels in both jowl fat and backfat compared with pigs fed beef tallow throughout all feeding phases. Although the current study did not look at this directly, feeding beef tallow for either a single period or the duration of the study had minimal changes on total SFA levels for all 3 depots evaluated.

Total MUFA was found to have an inverse relationship to total PUFA concentrations in all 3 fat depots evaluated in this study, which would agree with Benz et al. (2010). Feeding tallow maintained similar concentrations of total MUFA in all fat depots whether they were fed the additional fat for the duration of the study or only a single period when compared with those fed the control diet. However, pigs fed soybean oil had reduced levels of MUFA compared with pigs fed no additional fat or tallow. This would agree with Apple et al. (2009a), who found that feeding diets with animal fats elevated concentrations of MUFA whereas soybean oil reduced them.

The use of the biopsy technique and combining the barrow and gilt data could be considered limitations of this study. The use of biopsy technique allowed for serial collection of fat samples from the same pigs throughout the study; however, it prevented analysis of individual backfat layers. The inner backfat layer is more saturated with lower unsaturated fatty acids than the outer layer (Weber et al., 2006). By combining the 2 layers in the biopsy, it is possible that the proportion of inner and outer layer in each sample is not the same. The bar- row and gilt data were not reported separately because there were only 4 replications of each sex. Regardless, the data followed trends similar to those observed in previous research (i.e., gilts had decreased backfat, improved G:F, and a more unsaturated fatty acid profile in fat depots than barrows). Sex has a clear influence on composition of fat deposited with those with less backfat having a high percentage of PUFA and lower MUFA (Hallenstvedt et al., 2012). In the study herein, there were an equal number of barrows and gilts replicates in all of the reported data.

In conclusion, added fat, whether from tallow, soybean oil, or a blend of soybean oil and tallow, in some stages improved ADG and G:F. Feeding soybean oil will increase the amount of total PUFA in fat depots and consequently increase carcass fat IV; however, beef tallow can be used for improved growth characteristics without negatively impacting IV. Contrary to the other fat depots, jowl fat did not show a period effect and, therefore, the timing of feeding additional fat to pigs, whether it be early or in the final phase, does not have an altering affect in the overall fatty acid composition or IV in this fat depot. This illustrates the slower turnover rate of the jowl fat depot and explains the weak correlation between jowl fat and belly fat (Wiegand et al., 2011).

\section{LITERATURE CITED}

AOAC. 2006. Official methods of analysis. 18th ed. AOAC Int., Washington, DC.

Apple, J. K., C. V. Maxwell, D. L. Galloway, C. R. Hamilton, and J. W. S. Yancey. 2009a. Interactive effects of dietary fat source and slaughter weight in growing-finishing swine: III. Carcass and fatty acid compositions. J. Anim. Sci. 87:1441-1454. doi: $10.2527 /$ jas.2008-1455

Apple, J. K., C. V. Maxwell, D. L. Galloway, S. Hutchison, and C. R. Hamilton. 2009b. Interactive effects of dietary fat source and slaughter weight in growing-finishing swine: I. Growth performance and longissimus muscle fatty acid composition. J. Anim. Sci. 87:1407-1422. doi:10.2527/jas.2008-1453

Averette Gatlin, L., M. T. See, J. A. Hansen, D. Sutton, and J. Odle. 2002. The effects of dietary fat sources, levels, and feeding intervals on pork fatty acid composition. J. Anim. Sci. 80:1606-1615.

Bee, G., S. Gebert, and R. Messikomer. 2002. Effect of dietary energy supply and fat source on the fatty acid pattern of adipose and lean tissues and lipogenesis in the pig. J. Anim. Sci. 80:1564-1574.

Bee, G., R. Messikommer, and S. Gebert. 1999. Dietary fats and energy levels differently affect tissue lipogenic enzyme activity in finishing pigs. Fett/Lipid 101:336-342. doi:10.1002/(SICI)15214133(199909)101:9<336::AID-LIPI336>3.0.CO;2-Q

Benz, J. M., S. K. Linneen, M. D. Tokach, S. S. Dritz, J. L. Nelssen, J. M. DeRouchey, R. D. Goodband, R. C. Sulabo, and K. J. Prusa. 2010. Effects of dried distillers grains with solubles on carcass fat quality of finishing pigs. J. Anim. Sci. 88:3666-3682. doi:10.2527/jas.2010-2937 
Benz, J. M., M. D. Tokach, S. S. Dritz, J. L. Nelssen, J. M. DeRouchey, R. C. Sulabo, and R. D. Goodband. 2011a. Effects of choice white grease and soybean oil on growth performance, carcass characteristics, and carcass fat quality of growing-finishing pigs. J. Anim. Sci. 89:404-413. doi:10.2527/jas.2009-2737

Benz, J. M., M. D. Tokach, S. S. Dritz, J. L. Nelssen, J. M. DeRouchey, R. C. Sulabo, and R. D. Goodband. 2011b. Effects of increasing choice white grease in corn- and sorghum-based diets on growth performance, carcass characteristics, and fat quality characteristics of finishing pigs. J. Anim. Sci. 89:773-782. doi:10.2527/ jas.2010-3033

Browne, N. A., J. K. Apple, B. E. Bass, C. V. Maxwell, J. W. S. Yancey, T. M. Johnson, and D. L. Galloway. 2013a. Alternating dietary fat sources for growing-finishing pigs fed dried distillers grains with solubles: I. Growth performance, pork carcass characteristics, and fatty acid composition of subcutaneous fat depots. J. Anim. Sci. 91:1493-1508. doi:10.2527/jas.2012-5528

Browne, N. A., J. K. Apple, C. V. Maxwell, J. W. Yancey, T. M. Johnson, D. L. Galloway, and B. E. Bass. 2013b. Alternating dietary fat sources for growing-finishing pigs fed dried distillers grains with solubles: II. Fresh belly and bacon quality characteristics. J. Anim. Sci. 91:1509-1521. doi:10.2527/jas.2012-5529

Campbell, R. G., and M. R. Taverner. 1988. Genotype and sex effects on the relationship between energy intake and protein deposition in growing pigs. J. Anim. Sci. 66:676-686.

Coble, K. F., J. M. DeRouchey, M. D. Tokach, R. D. Goodband, J. C. Woodworth, and S. S. Dritz. 2015. Effects of 30\% dried distillers grains with solubles and $5 \%$ added fat prior to slaughter on growth performance and carcass characteristics of finishing pigs. J. Anim. Sci. 93(Suppl. 2):309. (Abstr.)

De la Llata, M., S. S. Dritz, M. D. Tokach, R. D. Goodband, J. L. Nelssen, and T. M. Loughin. 2001. Effects of dietary fat on growth performance and carcass characteristics of growingfinishing pigs reared in a commercial environment. J. Anim. Sci. 79:2643-2650.

Eggert, J. M., A. L. Grant, and A. P. Schinckel. 2007. Factors affecting fat distribution in pork carcasses. Prof. Anim. Sci. 23:42-53.

Hallenstvedt, E., N. P. Kjos, M. Overland, and M. Thomassen. 2012. Changes in texture, colour, and fatty acid composition of male and female pig shoulder fat due to different dietary fat sources. Meat Sci. 90:519-527. doi:10.1016/j.meatsci.2011.08.009

Jackson, A. R., S. Powell, S. L. Johnston, J. O. Matthews, T. D. Bidner, F. R. Valdez, and L. L. Southern. 2009. The effect of chromium as chromium propionate on growth performance, carcass characteristics, meat quality, and the fatty acid profile of fat from pigs fed no supplemented dietary fat, choice white grease, or tallow. J. Anim. Sci. 87:4032-4041. doi:10.2527/jas.2009-2168

Kellner, T. A., K. J. Prusa, and J. F. Patience. 2014. Impact of dietary fat source and concentration and daily fatty acid intake on the composition of carcass fat and iodine value sampled in three regions of the pork carcass. J. Anim. Sci. 92:5485-5495. doi:10.2527/jas.2014-7567

Kellner, T. A., K. J. Prusa, and J. F. Patience. 2015. The impact of dietary fat withdrawal on carcass iodine value, belly characteristics, and changes in body fat over time. J. Anim. Sci. 93:247257. doi:10.2527/jas.2014-7650
Lee, J. W., D. Y. Kil, B. D. Keever, J. Killefer, F. K. McKeith, R. C. Sulabo, and H. H. Stein. 2013. Carcass fat quality of pigs is not improved by adding corn germ, beef tallow, palm kernel oil, or glycerol to finishing diets containing distillers dried grains with solubles. J. Anim. Sci. 91:2426-2437. doi:10.2527/ jas.2012-5328

National Pork Producers Council. 2000. Composition and Quality Assessment Procedures. National Pork Board, Des Moines, IA.

NRC. 2012. Nutrient requirements of swine. 11th rev. ed. Natl. Acad. Press, Washington, DC.

Palmquist, D. L., and T. C. Jenkins. 2003. Challenges with fats and fatty acid methods. J. Anim. Sci. 81:3250-3254.

Paulk, C. B., J. R. Bergstrom, M. D. Tokach, S. S. Dritz, D. D. Burnett, E. W. Stephenson, M. A. Vaughn, J. M. DeRouchey, R. D. Goodband, J. L. Nelssen, and J. M. Gonzalez. 2015. Equations generated to predict iodine value of pork carcass back, belly, and jowl fat. J. Anim. Sci. 93:1666-1678. doi:10.2527/jas.2014-8400

Pettigrew, J. E., and M. A. Esnaola. 2001. Swine nutrition and pork quality: A review. J. Anim. Sci. 79(E. Suppl.):E316-E342.

Smith, J. W., II, M. D. Tokach, P. R. O’Quinn, J. L. Nelssen, and R. D. Goodband. 1999. Effects of dietary energy density and lysine:calorie ratio on growth performance and carcass characteristics of growing-finishing pigs. J. Anim. Sci. 77:3007-3015.

Van Soest, P. J. 1963. Use of detergents in the analysis of fibrous feeds. II. A rapid method for determination of fiber and lignin. J. Assoc. Off. Anal. Chem. 46:829-835.

Weber, T. E., B. T. Richert, M. A. Belury, Y. Gu, K. Enright, and A. P. Schinckel. 2006. Evaluation of the effects of dietary fat, conjugated linoleic acid, and ractopamine on growth performance, pork quality, and fatty acid profiles in genetically lean gilts. J. Anim. Sci. 84:720-732.

Widmer, M. R., L. M. McGinnis, D. M. Wulf, and H. H. Stein. 2008. Effects of feeding distillers dried grains with solubles, high-protein distillers dried grains, and corn germ to growing-finishing pigs on pig performance, carcass quality, and the palatability of pork. J. Anim. Sci. 86:1819-1831. doi:10.2527/jas.2007-0594

Wiegand, B. R., R. B. Hinson, M. J. Ritter, S. N. Carr, and G. L. Allee. 2011. Fatty acid profiles and iodine value correlations between 4 carcass fat depots from pigs fed varied combinations of ractopamine and energy. J. Anim. Sci. 89:3580-3586. doi:10.2527/ jas.2010-3303

Wood, J. D., R. I. Richardson, G. R. Nute, A. V. Fisher, M. M. Campo, E. Kasapidou, P. R. Sheard, and M. Enser. 2004. Effects of fatty acids on meat quality: A review. Meat Sci. 66:21-32. doi:10.1016/S0309-1740(03)00022-6

Xu, G., S. K. Baidoo, L. J. Johnston, D. Bibus, J. E. Cannon, and G. C. Shurson. 2010. The effects of feeding diets containing corn distillers dried grains with solubles, and withdrawal period of distillers dried grains with solubles, on growth performance and pork quality in grower-finisher pigs. J. Anim. Sci. 88:1388-1397. doi:10.2527/jas.2008-1403 